\title{
Daily scale wintertime sea surface temperature and IPC-Navidad variability in the southern Bay of Biscay from 1981 to 2010
}

\author{
G. Esnaola ${ }^{1}$, J. Sáenz ${ }^{2,3}$, E. Zorita ${ }^{4}$, A. Fontán ${ }^{1}$, V. Valencia ${ }^{1}$, and P. Lazure ${ }^{5}$ \\ ${ }^{1}$ AZTI-Tecnalia, Marine Research Division, Herrera Kaia Portualdea z/g, 20110 Pasaia, Gipuzkoa, Spain \\ ${ }^{2}$ Department of Applied Physics II, Fac. of Science and Technology, University of the Basque Country (UPV/EHU), \\ Barrio Sarriena s/n, 48940 Leioa, Spain \\ ${ }^{3}$ Research Center for Experimental Marine Biology and BioTechnology (PIE-UPV/EHU), Areatza Pasealekua, \\ 48620 Plentzia, Spain \\ ${ }^{4}$ Institute for Coastal Research, Helmholtz-Zentrum Geesthacht, Max-Planck-Straße 1, 21502 Geesthacht, Germany \\ ${ }^{5}$ Department DYNECO, IFREMER, Centre de Brest, BP 70, 29280 Plouzané, France
}

Correspondence to: G. Esnaola (gesnaola001@ikasle.ehu.es)

Received: 15 November 2012 - Published in Ocean Sci. Discuss.: 18 December 2012

Revised: 24 May 2013 - Accepted: 11 June 2013 - Published: 19 July 2013

\begin{abstract}
The combination of remotely sensed gappy Sea surface temperature (SST) images with the missing data filling DINEOF (data interpolating empirical orthogonal functions) technique, followed by a principal component analysis of the reconstructed data, has been used to identify the time evolution and the daily scale variability of the wintertime surface signal of the Iberian Poleward Current (IPC), or Navidad, during the 1981-2010 period. An exhaustive comparison with the existing bibliography, and the vertical temperature and salinity profiles related to its extremes over the Bay of Biscay area, show that the obtained time series accurately reflect the IPC-Navidad variability. Once a time series for the evolution of the SST signal of the current over the last decades is well established, this time series is used to propose a physical mechanism in relation to the variability of the IPC-Navidad, involving both atmospheric and oceanic variables. According to the proposed mechanism, an atmospheric circulation anomaly observed in both the $500 \mathrm{hPa}$ and the surface levels generates atmospheric surface level pressure, wind-stress and heat-flux anomalies. In turn, those surface level atmospheric anomalies induce mutually coherent SST and sea level anomalies over the North Atlantic area, and locally, in the Bay of Biscay area. These anomalies, both locally over the Bay of Biscay area and over the North Atlantic, are in agreement with several mechanisms that have separately been related to the variability of the IPC-Navidad, i.e. the south-westerly winds, the joint effect of baroclinic-
\end{abstract}

ity and relief (JEBAR) effect, the topographic $\beta$ effect and a weakened North Atlantic gyre.

\section{Introduction}

The Bay of Biscay is located in the intergyre zone of the North Atlantic, between the Azores current in the northern part of the subtropical gyre and the North Atlantic current in the subpolar gyre. The general circulation in the intergyre area is slack, especially in the Bay of Biscay. Here, the water circulation is characterised by a weak anticyclonic flow in the oceanic area (Pingree, 1993), a poleward slope current, slope water oceanic eddies, coastal upwelling in the western Iberian Peninsula, tidal flows, wind-induced currents and buoyant plumes (Pingree and Le Cann, 1989; Koutsikopoulos and LeCann, 1996). In particular, the slope current is characterised by its baroclinicity, generating eddies, fronts, meanders, instabilities and other related processes (Pingree and Le Cann, 1990; Coelho et al., 1999; Gil, 2003; Peliz et al., 2005, among others). Therefore, a complex overall pattern of processes is established in the continental slope of the Bay.

The poleward flow along the western Iberian margin was first reported by Frouin et al. (1990) and Haynes and Barton (1990), by using sea surface temperature (SST) satellite imagery and in situ measurements. Named the Iberian 
Poleward current (IPC) by Peliz et al. (2003) (Navidad or IPC-Navidad for its surface signal when entering the Bay of Biscay and surface signal of the IPC otherwise), this flow enters the Bay of Biscay around Cape Finisterre (NW Spain), and was first measured by Pingree and Le Cann (1990). Next, the warm and salty water flows eastward along the Cantabrian continental slope. Some flow continues poleward across the Armorican and Celtic slopes as noted by Pingree and Le Cann (1989, 1990), which estimated that the total slope transport at $48^{\circ} \mathrm{N}$ is approximately $4 \mathrm{~Sv}$. Since it is hindered by the abrupt changes of topography in locations such as canyons, the slope water is injected seaward to form slope water oceanic eddies (Garcia-Soto et al., 2002), the so-called swoddies (Pingree and Le Cann, 1992b).

The main forcing mechanisms of the IPC have been summarised by Coelho et al. (1999). The main mechanism for the generation of momentum has been attributed to the interaction of the meridional density gradient with the slope (Frouin et al., 1990). This is due to the geostrophic adjustment of the cross-shore density gradient that occurs when the large-scale eastward flow interacts with the slope of the N-S oriented coast (Relvas et al., 2007). This effect, the so-called JEBAR (joint effect of baroclinicity and relief), was theoretically described by Huthnance (1984). Another forcing mechanism is the wind-stress curl and its related poleward Sverdrup transport (Haynes and Barton, 1990; Le Cann and Serpette, 2009). Torres et al. (2003) concluded that the large-scale meridional density gradient is the main driving mechanism and that interannual IPC variability may be influenced by anomalous winds.

Pingree and Le Cann (1990) noted that, although the mean slope current is relatively weak $\left(5-10 \mathrm{~cm} \mathrm{~s}^{-1}\right)$, it is markedly seasonal with warm surface water flowing along the Portuguese and the northern Spanish slopes in winter. In summer, the fate of the poleward flow is still debated (Relvas et al., 2007). Pingree (1993) noted that surface flow in northwestern Spain is significantly seasonal as indicated by seasonal changes in mean wind stress. Between February and October, the Azores High intensifies and the pressure gradient around the High also increases. This implies southward winds off the Portuguese coast, winds that cause upwelling and southward directed surface flows, particularly in summer. In winter, when the Azores High weakens, the southward component of the wind stress relaxes or even changes sign, allowing the extension of a surface warm poleward current. Therefore, there is a reversal of surface flow off the Portuguese slopes between summer (southward flow) and winter (poleward flow). Recently, Peliz et al. (2005) have proposed a seasonal cycle of development and decay of the poleward current in the western Iberian Peninsula, based on previous studies (Frouin et al., 1990; Haynes and Barton, 1990). The phase of development implies the strengthening of the meridional density gradients during late autumn and winter within the western Iberian Basin; the development of the IPC as a tongue-like structure as described in Frouin et al. (1990); and the development of the turbulent character of the IPC. On the other hand, the decay phase is related to the weakening of the meridional density gradients in late winter; the broadening of the warm tongue and erosion of the near-surface thermohaline structure by the action of wind stress and interactions in the mesoscale eddy field; the offshore drift of the tongue and individual eddies (Pingree and Le Cann, 1990; Pingree et al., 1999; Peliz et al., 2005). The latter authors hypothesised that the poleward flow does not reverse but that the core is moved offshore.

The estimations of the interannual variability of the IPC and its surface signal (IPC-Navidad) have mostly been based on differences of SST between offshore zones by the coast and open ocean areas (zonal or meridional differences depending on the location) (Pingree and Le Cann, 1992a; Peliz et al., 2005; deCastro et al., 2011) and also on collections of individual satellite SST images (Pingree, 1994; GarciaSoto et al., 2002; Garcia-Soto, 2004). An estimation of that variability which included the related salinity variability in addition to that of the temperature, was also given by Llope et al. (2006) based on in situ vertical temperature and salinity profiles. More recently, and based on a double variable approach, Le Hénaff et al. (2011) used a combination of two indices to deduce a monthly winter IPC occurrence time series over the 1992-2002 period. The first index is based on Topex/Poseidon satellite single track (137) and it describes the geostrophic current anomaly. A second index is based on remote-sensed SST anomaly measured across the same satellite track. They found good agreement between the two indices for the strongest 1995/1996 and 1997/1998 IPC episodes, but also some discrepancies, especially after 1999.

The relation of the interannual variability of the IPCNavidad with the North Atlantic Oscillation (NAO) index has been described in Garcia-Soto et al. (2002) and GarciaSoto (2004). These authors found that January warming in the southern Bay of Biscay during exceptional IPC years was correlated with negative NAO index of the preceding months (November to December), indicating a relation between integrated effects of negative NAO phases from previous months on the ocean and the state of the IPC in January. The interannual variability of the SST in the area was also found to be anti-correlated with the preceding December NAO index over the 1965-2003 period by Michel et al. (2009), for all seasons in this case. The state of the IPC in January was also found by Le Cann and Serpette (2009) and Le Hénaff et al. (2011) to be partly related to the NAO index from preceding months. However, they concluded that the intensity of the IPC is not associated with the amplitude of the NAO index. Llope et al. (2006), in contrast, did not find a relationship with the NAO in their study based on temperature and salinity data. In addition to NAO, deCastro et al. (2011) also found a relation with the November-December eastern Atlantic-western Russia (EA/WR) teleconnection pattern. Pingree (2002) found similar anti-correlation between 
the NAO index and the poleward eastern boundary current at larger scale, from Portugal to Scotland.

Daily infrared SST satellite products that cover more than the last three decades have shown to be a valuable tool for the detection of the surface signal of the IPC (Pingree and Le Cann, 1989; Frouin et al., 1990; Haynes and Barton, 1990; Pingree and Le Cann, 1990, 1992a,b; Garcia-Soto et al., 2002; Garcia-Soto, 2004; Torres and Barton, 2006; Le Cann and Serpette, 2009, among others). In many cases, however, those images suffer from a high percentage of missing data, mostly due to the presence of clouds at the time they were remotely sensed. This fact has led to the use of time averaged SST images or sparse exceptionally clear SST images in most studies related to the IPC-Navidad. The first step of the present study will be to surpass the problem of the high percentages of missing data using the DINEOF (data interpolating empirical orthogonal functions) technique to reconstruct as much as possible wintertime infrared SST images. In addition, it will be tested whether it is reasonable to combine microwave and infrared remotely sensed SST images within the DINEOF technique as a way to enhance the number of reconstructed infrared images. The rationale behind this idea is that the number of missing data in the microwave based dataset is much smaller. All deduced reconstructions will be validated using satellite-independent in situ data.

A principal component analysis (PCA) will then be applied to the reconstructed and validated SST images to identify the surface signal of the IPC on the SST images. The first EOF and its time expansion series will be shown to properly characterise the IPC-Navidad phenomenon by both the comparison with previous studies and the use of in situ temperature and salinity data. Once the IPC-Navidad time evolution time series has been established, its extreme positive and negative values will be used to deduce the related atmospheric and oceanic conditions.

Accordingly, the objectives of this study are the following ones. First, to obtain as many as possible missing data free wintertime SST images for the Bay of Biscay area applying the DINEOF reconstruction technique. The second objective consists in testing if the combined reconstruction of microwave and infrared SST images leads to any improvement compared to reconstructing only infrared images. The third objective tries to identify the IPC-Navidad signal on the reconstructed datasets by deducing a daily frequency series of its occurrence for the winters in the 1981-2010 period, validating it based on satellite independent in situ data. Finally, the fourth objective consists in deducing the atmospheric and oceanic conditions that enhance or prevent the major IPC episodes. They are analysed within the context of the IPC driving mechanisms proposed in previous studies. To this end, the variety of the datasets used and the DINEOF reconstruction technique are described in Sect. 2 and the results are presented in Sect. 3. Sect. 3.1 deals with the reconstructions of SST datasets and the validation of the reconstructed data, whilst Sect. 3.2 shows the deduction and validation of the IPC-Navidad time series. Finally, Section 3.3 deals with the atmospheric and oceanic conditions related to the IPC. A discussion follows in Sect. 4 and the final conclusions are given in Sect. 5.

\section{Data and methodology}

\subsection{Data}

The variety of the data sources used in this study is described in the following. First the satellite SST datasets to which the missing data reconstructing technique will be applied are described, followed by the description of the in situ measured SST dataset used for the verification of such reconstructions. Next, the reanalysis products used to study the influence of the atmosphere on the major SST variability modes are described. The properties of a satellite sea level anomaly (SLA) dataset used for the same purpose are also detailed. Finally, an in situ profile dataset used to obtain the vertical distributions of temperature and salinity related to the main SST variability pattern is detailed.

Two sources of remotely sensed nighttime SST images covering the southern Bay of Biscay study area (Fig. 1) have been used in this study. One is based on measurements in the infrared spectral band. The second is based on the microwave band. The differing characteristics of the two datasets and their relative advantages and disadvantages are summarised in the following, paying special attention to their spatial resolutions and time coverages.

The first source of SST images is the AVHRR (Advanced Very High Resolution Radiometer) Pathfinder v5.2 product (Casey et al., 2010), which offers nearly 30 complete years of $4 \mathrm{~km}$ resolution daily SST images retrieved from infrared band radiometer measurements for the 1981-2010 period. The product also offers a full set of eight quality flags describing the reliability of each of the SST retrievals, going from 0 (lowest quality) to 7 (highest quality). Wintertime daily nighttime SST images were chosen for this study (ftp://ftp.nodc.noaa.gov). This choice strongly conditions the number of available SST retrievals but ensures the use of the best possible dataset in the application of the SST image reconstruction technique.

The second source of SST images is the v7 product derived from measurements by the Advanced Microwave Scanning Radiometer (AMSR-E) on board the Aqua satellite (http://www.ghcc.msfc.nasa.gov/AMSR/). With a $0.25^{\circ}$ spatial resolution, daily images are available starting in June 2002. Files for the 2002-2010 period were obtained (ftp: //ftp.ssmi.com) and processed to obtain winter (Nov-DecJan-Feb) nighttime daily images for the study area.

The Pathfinder SST image series, compared to those from AMSR-E, have the advantages of covering a longer period (1981-2010 compared to 2002-2010) and having a higher spatial resolution ( $4 \mathrm{~km}$ compared to $0.25^{\circ}$ ). However, these 
images, derived from measurements in the infrared band also have a major disadvantage compared to the microwave retrievals since SST estimations are missing in the presence of clouds. Although AMSR-E images will contain missing values due to the occurrence of rain, strong winds $\left(>20 \mathrm{~m} \mathrm{~s}^{-1}\right)$, sun glint or in areas near the coast $(\sim 75 \mathrm{~km})$, the overall percentage of missing data is considerably smaller compared to the Pathfinder dataset. Despite their lower resolution and lack of measurements in locations near the coast, this property makes them a potentially valuable source of information to complement other higher resolution SST images with high percentages of missing data. Accordingly, instead of filling in missing values in AMSR-E data, the technical approach applied here is to use that available information in the reconstruction of missing Pathfinder data.

Once the reconstruction technique was applied to SST images and missing data was filled in, reconstructed SST fields have to be verified, preferably against independent data. In situ SST measurements from the International Comprehensive Ocean-Atmosphere Data Set, ICOADS (Worley et al., 2005; Woodruff et al., 2011), were used for that purpose. Although observations from this source had already been used as an ensemble in the statistical procedure applied in the calibration of the algorithms used to retrieve SST from satellite measurements (Kilpatrick et al., 2001), and thus are not fully independent from satellite SST retrievals, individual in situ SST casts corresponding to the study area were used as a satellite independent source of information in the verification processes.

To check the oceanic vertical structure and the properties of water masses related to the main SST variability mode given by the PCA of the reconstructed Pathfinder SST data, vertical temperature and salinity profiles from the World Ocean Database (WOD) (http://www.nodc.noaa.gov/ OC5/WOD09/pr_wod09.html) were obtained for the study area, and subsets for the 4 different areas shown in Fig. 1 were selected. Wintertime profiles for standard depth levels corresponding to OSD (ocean station data: bottle, low resolution CTD/XCTD), CTD (high resolution CTD/XCTD) and PFL (profiling floats) instrumental sets (see Johnson et al., 2009, for details) and containing both temperature and salinity records were selected for the 1981-2010 period. Data for the 4 areas (I, II, III and IV) shown in Fig. 1 were separately analysed.

To study the covariability of the atmosphere and the wintertime SST in the area, atmospheric variables from the ERAInterim reanalysis (Simmons et al., 2007) were obtained for the North Atlantic area $\left(55^{\circ} \mathrm{W}-11^{\circ} \mathrm{E} 29-71^{\circ} \mathrm{N}\right)$. Nighttime anomalies of the ERA-Interim turbulent surface heat-fluxes $\left(\mathrm{W} \mathrm{m}^{-2}\right)$, the surface pressure $(\mathrm{hPa})$ and the two components of the surface wind stress $\left(\mathrm{N} \mathrm{m}^{-2}\right)$, all with a $0.7^{\circ}$ horizontal resolution, were obtained for the 1980-2011 period by removing the daily climatology (daily seasonal cycle). The surface turbulent heat fluxes, defined as positive when going

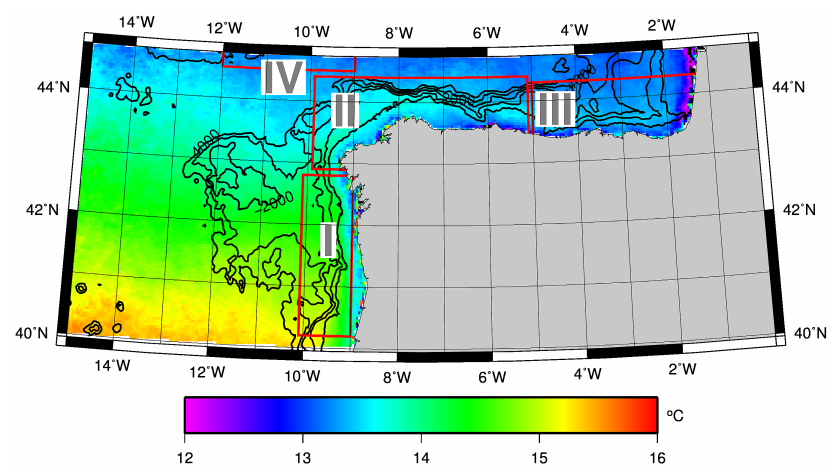

Fig. 1. The main study area with the mean December-January SST distribution. Boxes I to IV will be used to create separated vertical temperature and salinity datasets based on the Word Ocean Database individual casts. Area IV $\left(12.0-9.0^{\circ} \mathrm{W}, 44.5-46.5^{\circ} \mathrm{N}\right)$ is only partially shown. The 1000 to $4000 \mathrm{~m}$ depth contours are shown with a $1000 \mathrm{~m}$ depth interval, and the $200 \mathrm{~m}$ depth contour is also shown.

into the ocean, are the sum of the surface latent and sensible heat fluxes.

Additionally, $1.25^{\circ}$ resolution daily anomalies of the geopotential height of the ERA-Interim $500 \mathrm{hPa}$ pressure level $Z(\mathrm{~m})$ were retrieved for the same period and area. The maximum values of the 3-10 day band-pass filtered intramonthly standard deviations of such anomalies indicate the approximated location of the Northern Hemisphere storm track for each month (Lau, 1988; Rogers, 1997). In order to have a daily time evolution of that approximated location, 30 day moving standard deviations were used.

Daily scale sea surface gridded altimetry products (derived from 7 daily products) were also obtained from AVISO (http: //www.aviso.oceanobs.com) for the 1992-2010 period. The selected variables were the SLA and the related geostrophic current anomalies, but the absolute dynamic topography (ADT) was also obtained. The selected branch comprises delayed time data from different satellites (Topex/Poseidon, ERS-1/2, Jason-1, Envisat and OSTM/Jason-2) that are merged following a criteria for maximum temporal homogeneity ("reference" data). A detailed description of this dataset can be found in AVISO (2012). The seasonal cycle was removed from both variables along with the long-term trend.

\subsection{Methodology}

Initially described by Beckers and Rixen (2003) and AlveraAzcárate et al. (2005), the DINEOF technique is an iterative methodology to fill in missing data in geophysical datasets. The technique initially sets missing values to zero value. Then the dataset is iteratively decomposed by means of a principal component analysis (e.g. von Storch and Zwiers, 1999; Wilks, 2006) and recomposed afterwards using a fixed number of EOFs until convergence is achieved. The iterative 
process is repeated using a different number of EOFs in each realisation. The optimal number of EOFs is determined by means of cross validation using part of the initially nonmissing data that is put aside for this purpose. Once the optimal number of EOFs is determined, a final reconstruction is conducted using all available non-missing data and the optimal number of EOFs previously identified.

The methodology was additionally improved by AlveraAzcárate et al. (2009) to reduce spurious time variability by including a filtering of the time covariance matrix that leads to better quality reconstructions. Examples of the application of the DINEOF technique can be found for the Adriatic Sea in Alvera-Azcárate et al. (2005), for the Ligurian Sea in Beckers et al. (2006), the Gulf of Mexico in Alvera-Azcárate et al. (2007) or the Black Sea in Alvera-Azcárate et al. (2009) among others. In the case of the Bay of Biscay and the surrounding areas, examples of DINEOF application can also be found in Sánchez et al. (2007), Ganzedo et al. (2011) or in Esnaola et al. (2012).

When applying the DINEOF technique to a dataset containing high percentages of missing data, it must be taken into account that the technique fills in missing values based on the available non-missing data. Frames (a time snapshot) containing percentages of valuable information below a given threshold have to be disregarded, as their inclusion would worsen the overall skill of the reconstruction. A $5 \%$ threshold of available non-missing data has been shown to be a reasonable choice (Alvera-Azcárate et al., 2005; Beckers et al., 2006) and was also used in this study. This means that only Pathfinder images belonging to days having nonmissing data on at least a $5 \%$ of the over ocean pixels were reconstructed. In case of the combined Pathfinder and AMSR-E reconstruction, days having a joint $5 \%$ percentage of non-missing data were also reconstructed, leading to a higher number of reconstructed days compared to the reconstruction based solely on the Pathfinder data.

\section{Results}

\subsection{Sea surface temperature reconstructions}

The periods covered by the two satellite wintertime SST image sources, AVHRR Pathfinder v5.2 and AMSR-E, were 1981-2010 and 2002-2010, respectively. Based on that time coverage, two main DINEOF reconstructions and one supplementary reconstruction were carried out. DINEOF was first applied to the full Pathfinder data covering almost $30 \mathrm{yr}$. For the period shared by the two data sources, 2002-2010, a combined DINEOF reconstruction (Alvera-Azcárate et al., 2007) was then conducted, making use of the available AMSR-E data in the Pathfinder-based reconstruction. Finally, in order to have a mean to evaluate the impact of the inclusion of the AMSR-E data in the combined reconstruc- tion over the 2002-2010 period, DINEOF was additionally applied solely to the the Pathfinder over the same period.

It was previously stated in the methodology section that only SST images with less than $95 \%$ of missing data were reconstructed. That means that only days with at least $5 \%$ of available data were reconstructed for the two Pathfinder subsets (at least $5 \%$ of quality flag 7 data available). In the case of the combined Pathfinder and AMSR-E reconstruction, the days that did not match that criteria but that had a joint proportion of $5 \%$ available data were also reconstructed. The overall percentage of missing data (lower than quality flag 7) in the Pathfinder dataset in the study area in wintertime over $1981-2010$ is $93.2 \%$, in the set over 2002-2010 it is $92.6 \%$ and finally in the AMSR-E dataset it is $57.1 \%$. The number of days in each of the reconstructions matching the $5 \%$ percentage threshold are shown in the top row of Table 1 (days), together with the percentage they represent with respect to the total amount of days in the period (in brackets). These percentages show that for the wintertime period, even allowing a threshold as high as a $95 \%$ of missing data, the percentage of days trespassing the criteria remains low. However, the combined case shows the advantage of increasing that amount by approximately $4 \%$. For all the reconstructions, the percentage of the overall variance contained in the original datasets that was explained by their reconstructed counterparts was above the $99 \%$.

The rest of the Table 1 lists the values of the verification indices computed using the in situ SST measurements from the ICOADS dataset. Based on the date and geographic location of each individual ICOADS observation, a check for the presence of a non-missing value was performed in the nearest neighbour satellite pixel and a verification sub-sample of $\mathrm{N}$ pairs of coincident values created. For each of these sub-samples two verification indices were then computed: the bias (BIAS) and the median absolute deviation (MAD), which is qualitatively similar to the root mean squared error (RMSE) but less sensitive to outliers (Wilks, 2006). For each of the reconstructions, two verification sub-samples were selected. The first compared the originally non-missing satellite values with the available ICOADS counterparts (SATELLITE). A second comparison was made between all coincidences of the reconstructed and the in situ datasets (DINEOF).

The BIAS and MAD values in the SATELLITE columns give the approximated expected background differences between the in situ measurements and the satellite retrievals. It can be seen that DINEOF introduces a small negative BIAS in the $0.12-0.14{ }^{\circ} \mathrm{C}$ range. The MAD values of the reconstructed datasets remain nearly unchanged with respect to the original satellite and in situ value differences. Consequently, the verification Table 1 lists that error indicators are only slightly modified by the application of the DINEOF technique on the satellite data. It also shows nearly identical values for the 2002-2010 Pathfinder combined and noncombined reconstructions, indicating that the inclusion of the 
Table 1. Verification of the 1981-2010 Pathfinder, 2002-2010 Pathfinder and the 2002-2010 combined Pathfinder/AMSR-E DINEOF reconstructions using ICOADS SST data. In all three cases in situ observations are compared with the originally non-missing satellite values (SATELLITE) and with the fully reconstructed dataset (DINEOF). The number of reconstructed days together with the percentage of the total they represent in brackets, the sample size of each verification sub-sample (N), the bias (BIAS) and the median absolute deviation (MAD) are shown.

\begin{tabular}{|c|c|c|c|c|c|c|}
\hline & \multicolumn{2}{|c|}{ 1981-2010 Pathfinder } & \multicolumn{2}{|c|}{ 2002-2010 Pathfinder } & \multicolumn{2}{|c|}{ 2002-2010 Pathfinder/AMSR-E } \\
\hline & SATELLITE & DINEOF & SATELLITE & DINEOF & SATELLITE & DINEOF \\
\hline Days & $1256(35.5 \%)$ & $1256(35.5 \%)$ & $418(40.9 \%)$ & $418(40.9 \%)$ & $460(45.0 \%)$ & $460(45.0 \%)$ \\
\hline $\mathrm{N}$ & 8807 & 42458 & 2832 & 16733 & 2919 & 18336 \\
\hline $\operatorname{BIAS}\left({ }^{\circ} \mathrm{C}\right)$ & -0.19 & -0.31 & -0.18 & -0.32 & -0.18 & -0.31 \\
\hline $\operatorname{MAD}\left({ }^{\circ} \mathrm{C}\right)$ & 0.47 & 0.46 & 0.24 & 0.27 & 0.24 & 0.26 \\
\hline
\end{tabular}

microwave satellite data in the reconstruction does not have a negative impact in its quality, but it increases the number of reconstructed days from 418 to 460 .

The results shown in Table 1 correspond to the reconstructions based on quality flag 7 Pathfinder database values. Three additional analogous reconstructions were also computed (not shown) jointly using Pathfinder quality 5, 6 and 7 data. Due to the inclusion of new non-missing values, the percentages of reconstructed days increased, but this led to an increase in the values of the error indicators, especially the BIAS. In view of these results, and to ensure the use of the best available SST images in the subsequent sections, only quality flag 7 data were subsequently used in spite of decreasing the number of reconstructed days.

In addition to the verification indices given in Table 1, another two measures of the skill of the reconstructions are given in Figs. 2 and 3. First, in Fig. 2, as an indicator of the spatial distribution of the error introduced by the reconstruction technique, BIAS and MAD spatial maps obtained comparing originally non-missing satellite values with their reconstructed counterparts are shown (DINEOF technique was not required to retain the originally non-missing values unchanged). Figure 3 shows the time series of the BIAS and MAD values illustrating the time evolution of the errors, and also the number of observations used to deduce them. As in Table 1, the values obtained for the two combined and noncombined 2002-2010 reconstructions were very similar and thus only those belonging to the combined reconstruction are shown in both cases.

BIAS values in Fig. 2 lay between a $\pm 0.25^{\circ} \mathrm{C}$ range in most of the cases. Highest negative values are observed in the eastern corner of the Bay and positive ones in the western Iberian coast and also in the south-western corner in the case of the combined reconstruction. MAD values below $0.2{ }^{\circ} \mathrm{C}$ are more spatially homogeneous with highest values found in the western Iberian coast. However, no spatially remarkable pattern is found in the spatial error maps, which indicates that DINEOF does not introduce any specific spatial error signature with respect to the originally non-missing satellite values.
Considering, as in Table 1, the comparison with in situ observations from ICOADS dataset, Fig. 3 shows the monthly evolution of the error parameters. Again, the background error, i.e. the comparison of the originally non-missing satellite values and ICOADS observations (SATELLITE), and the errors of the reconstructions versus ICOADS observations (DINEOF) are shown (blue and red lines respectively). The time axes are arranged so that each space between the dashed vertical lines shows a November to February period (both included), and the same time axis is used for the 1981-2010 and 2002-2010 cases. BIAS values related to both reconstructions are mostly negative and lie between $0.2-0.4{ }^{\circ} \mathrm{C}$ values. However, there are important exceptions with considerably higher BIAS values in the case of the 1981-2010 reconstruction, specially in the initial years, and also in some months in the 1992-1998 period. Although this could cause some concern on the quality of the reconstruction in these months, it has to be stressed that in almost all those cases with high BIAS values, the comparison of the originally non-missing satellite data and the in situ observations yields equally high BIAS values. This indicates that the error does not arise from the reconstruction itself but from prior discrepancies between satellite and in situ observations. The evolution of MAD values show a clear descending trend in the case of the Pathfinder alone reconstruction, and more constant levels with values in the $0.2-0.5^{\circ} \mathrm{C}$ range for the combined 2002-2010 reconstruction. The decreasing trend in the 1981-2010 reconstruction seems to be related to both the increase of the number and the quality of in situ observations. In most cases, peaks with large MAD values in the SATELLITE original data are smoothed in the DINEOF reconstruction.

Table 1 and Figs. 2 and 3 show that the error estimations of the reconstructions based on the Pathfinder quality flag 7 data computed using the DINEOF technique are similar to the ones of the original raw data. These reconstructed datasets, however, offer a much larger amount of data compared to their original raw data analogues. These results support the use of the reconstructions in the forthcoming steps in this study. The main wintertime SST variability mode and its 

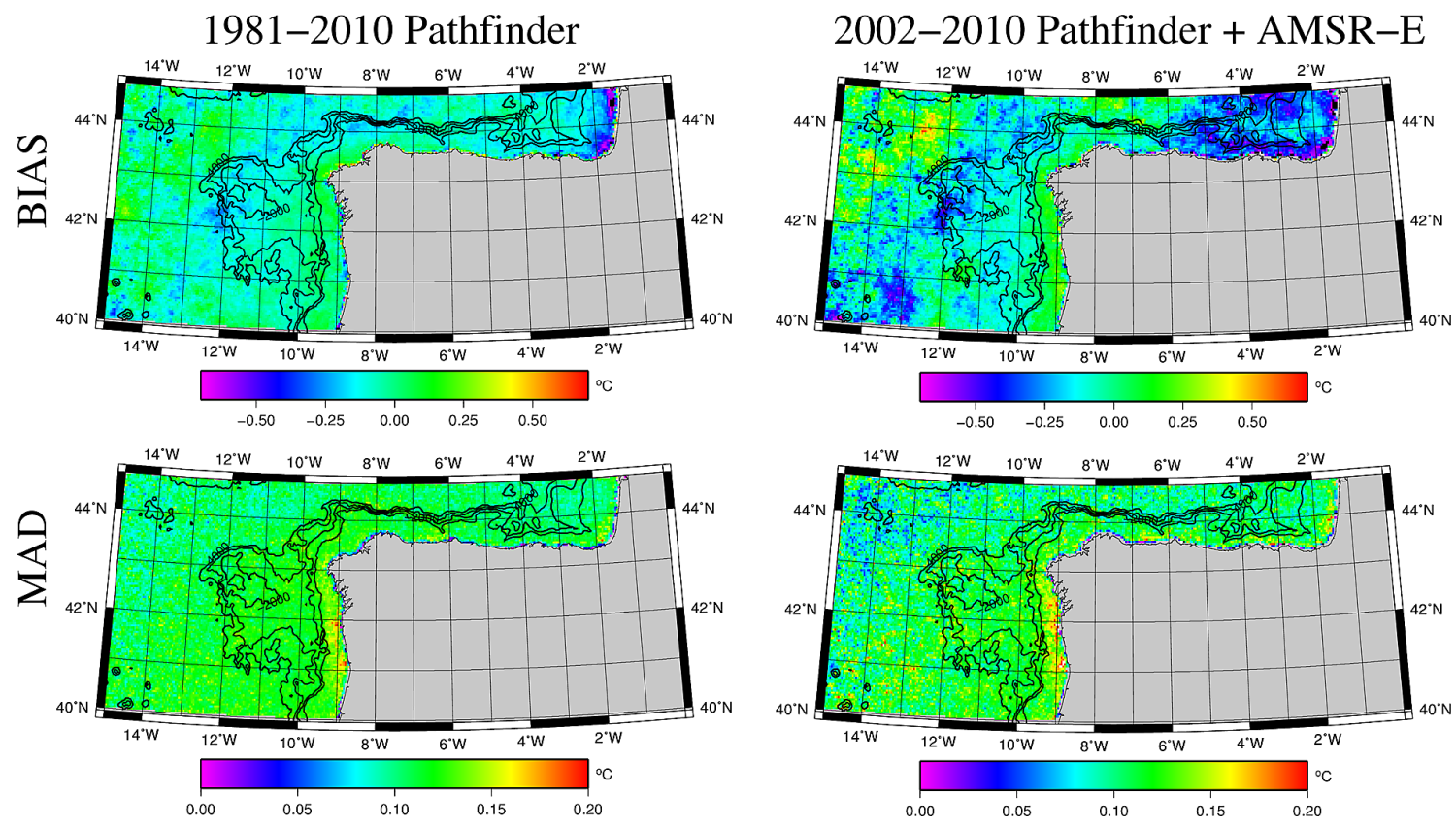

Fig. 2. BIAS $\left({ }^{\circ} \mathrm{C}\right.$, top panels) and $\mathrm{MAD}\left({ }^{\circ} \mathrm{C}\right.$, bottom panels) error distribution maps obtained comparing originally non-missing satellite data with their reconstructed counterparts. The left panels show error maps for the 1981-2010 Pathfinder alone reconstruction and the right ones those of the combined Pathfinder AMSR-E reconstruction.

relation with the Iberian Poleward Current and its variability are studied in the following, based on the reconstructed SST data.

\subsection{Sea surface temperature variability and the surface signal of the IPC}

The main wintertime SST variability mode, obtained from a PCA analysis of the reconstructed datasets, will be analysed in this section. In relation to this mode, the surface temperature pattern and the time evolution at different timescales, as well as the water mass properties related to them, will be shown to match the properties inferred from several previous studies for the Iberian Poleward Current. Due to its time span of nearly 30 winters, and the approximately 1250 SST images it contains, the analysis will be mainly based on the 1981-2010 Pathfinder reconstruction.

The characteristic SST patterns related to a well developed IPC episode, and the presence of the surface signal of this phenomenon in the reconstructed datasets, is evident in the results from two selected previous studies based on gappy SST data which are reproduced here. These two examples will also be used to introduce the problem of identifying the IPC-Navidad signal in SST anomaly patterns.

The SST anomaly maps were computed subtracting a 15 day running-mean climatology derived from the individual daily SST images. Due to the recurrence properties of the IPC, part of its signal is present in the raw daily climatology, and accordingly the smoothing ( 15 day running mean) is an attempt to remove that presence. The presence of the surface signal of the IPC can be detected in the composed DecemberJanuary mean of the daily smoothed SST climatology shown in Fig. 1, where a relatively warmer water intrusion can be detected off the northern Iberian coast. The image shows that even after such smoothing a weak IPC-Navidad signal still remains in the daily climatology, and thus anomalies must be interpreted with care. It is also remarkable that the daily climatology shows the presence of colder waters near the western and north-western Iberian coast. This may have two origins. The first one comes from the upwelling events related to northerly and north-easterly winds. The second is the Western Iberian Buoyant Plume (WIBP) of riverine origin trapped by the coast by the effect of the IPC, described by Peliz et al. (2005). The detection of the IPC-Navidad in the climatological mean could introduce some distortion in the interpretation of the anomalies. Although some drawbacks are related to the daily climatology used in this study, it will be shown that this climatology is consistent enough to characterise the IPC SST signal in terms of SST anomalies if the mentioned limitations are borne in mind.

deCastro et al. (2011) showed, using January mean SST maps computed from Pathfinder v5.0 data with missing values, years with and without evidence of the surface signal of the IPC (their Figs. 3 and 4). Here 1987, 1990, 1996 and 2005 Januaries were selected, the second and the third being months with evidence of IPC-Navidad development and the other two without any clear evidence. Figure 4 shows 3 maps (panels) for each of these years (rows). The left panels show the mean January SSTs computed from Pathfinder 

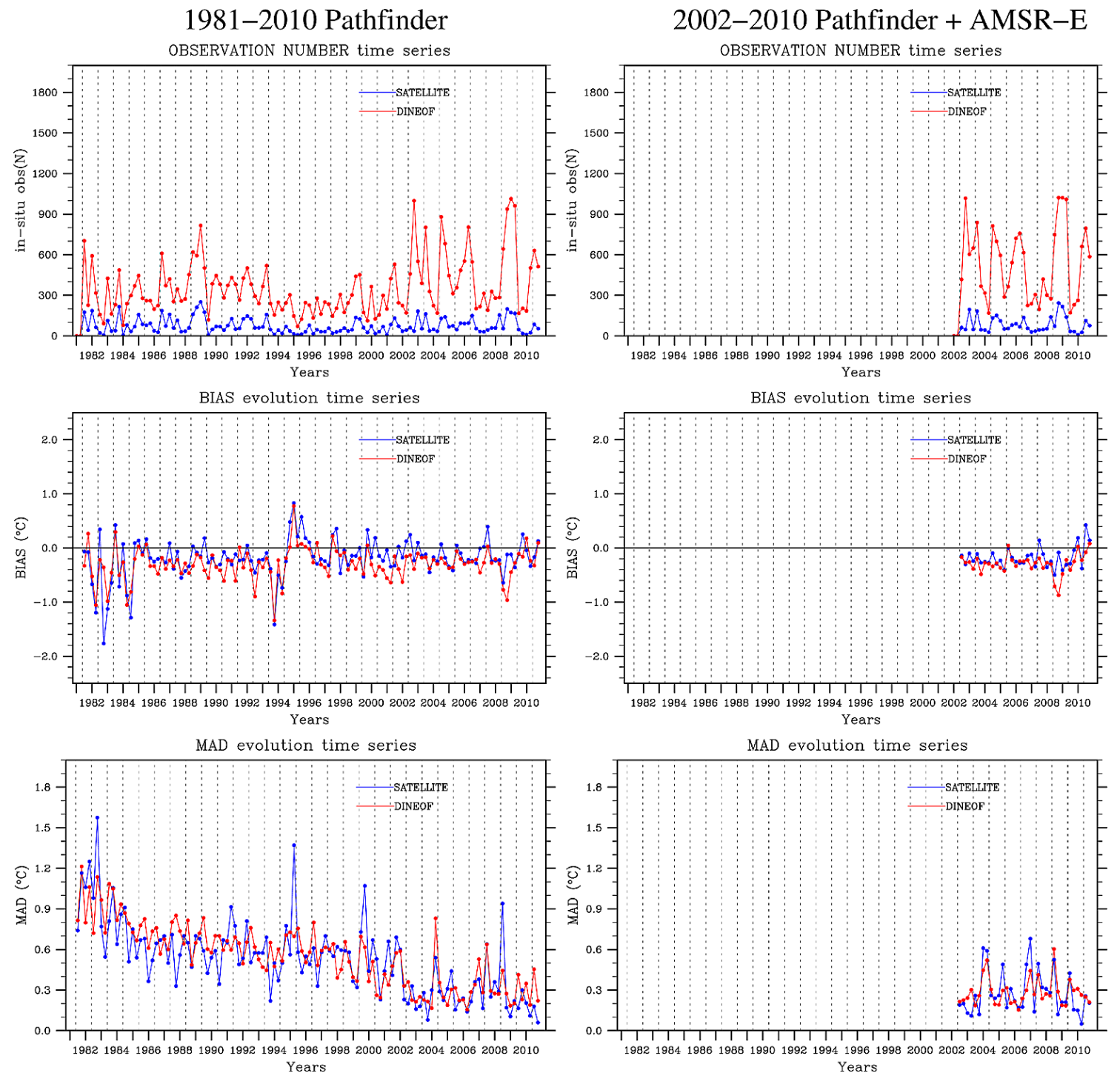

Fig. 3. Time evolution of the monthly number of observations (top panels), the bias (middle panels) and MAD (bottom panels) error estimates. Panels are organised as in Fig. 2. Blue lines indicate estimates obtained from data pairs of originally non-missing satellite data and their ICOADS counterparts while the red ones indicate the same but for the reconstructed datasets. The same time axis is used for the 1981-2010 and the 2002-2010 reconstructions in order to allow an easier comparison.

v5.2 quality flag 7 gappy data and the middle panels show the same January means but computed from the reconstructed data. Figures from 1990 and 1996 effectively show the presence of $14-15^{\circ} \mathrm{C}$ temperature surface waters near the western, and specially by the northern, Iberian coast, whereas their 1987 and 2005 analogues show equivalent $11.5-13^{\circ} \mathrm{C}$ surface temperatures. The analogues of these results computed from the SST anomalies are given in the panels on the right. Positive $0.5-1.5^{\circ} \mathrm{C}$ anomalies are related to the presence of the IPC-Navidad, both near and off the western and northern Iberian coasts, and are stronger in the north.

Figure 5 is related to two SST images that can be found in Le Cann and Serpette (2009) (Fig. 1b) and in Garcia-Soto and Pingree (2012) (Fig. 10b), but it also has the aim to illustrate the potential of the use of daily SST images. The figures in Le Cann and Serpette (2009) and Garcia-Soto and Pingree (2012) show a well developed IPC-Navidad event on 14 December 2006. Figure 5 shows individual SST (top panels) and SST anomaly (bottom panels) maps for the 12, 14 and 16 of that month. The shape of the SST patterns is very similar to that shown in the mentioned references, including the meandering behavior off the continental slope related to the generation of swoddies (Pingree and Le Cann, 1992b; Garcia-Soto et al., 2002). The SST anomaly patterns are also consistent with the previous anomaly patterns shown in the right panels of Fig. 4. Additionally, Fig. 5 shows an intensification of 

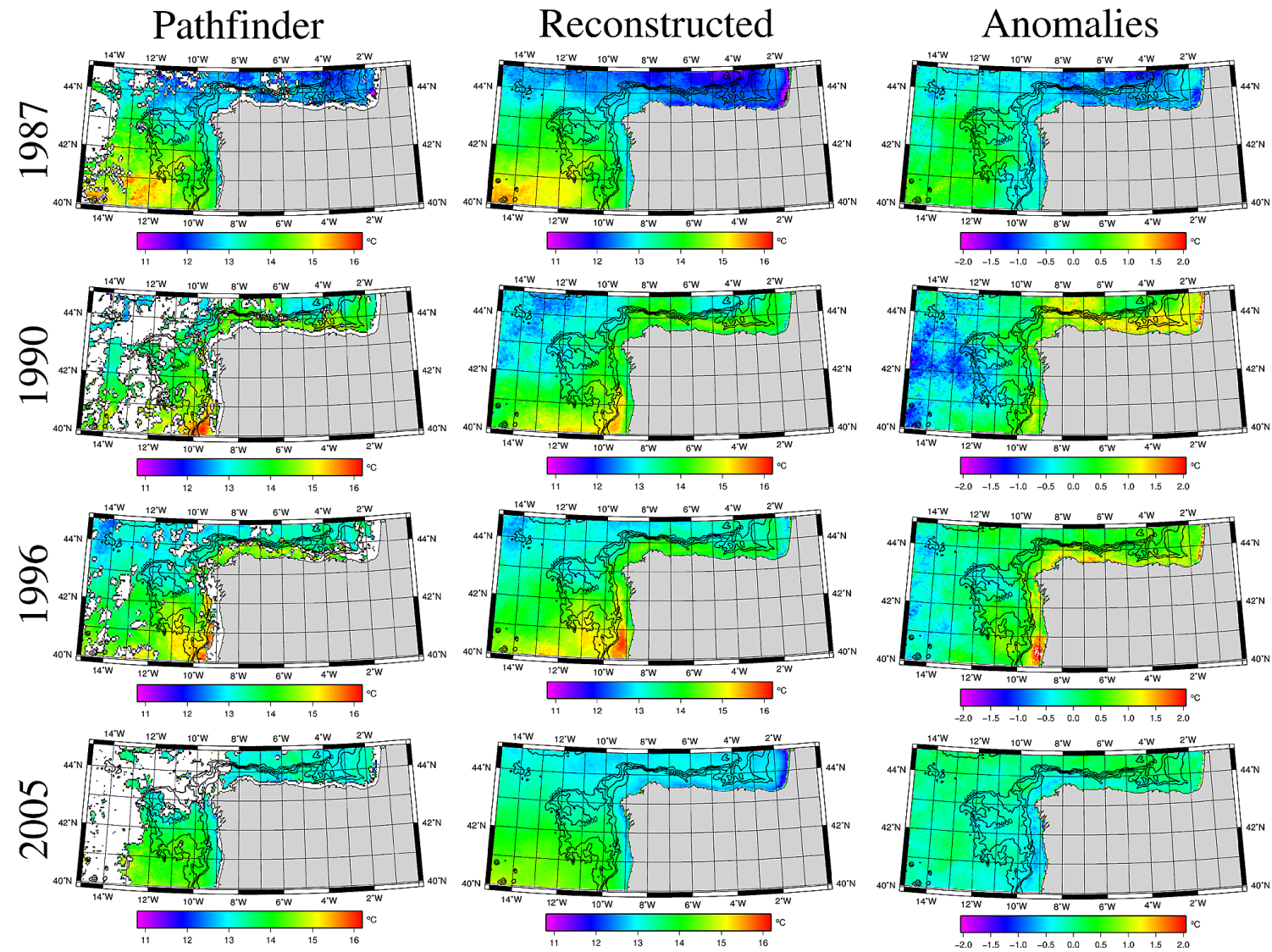

Fig. 4. January SST fields for 1987, 1990, 1996 and 2005. The left panels show the mean of un-reconstructed flag 7 (best quality only) Pathfinder values of the respective year, the middle panels as well but reconstructed using DINEOF and the panels on the right also the same but after the climatological mean has been removed.
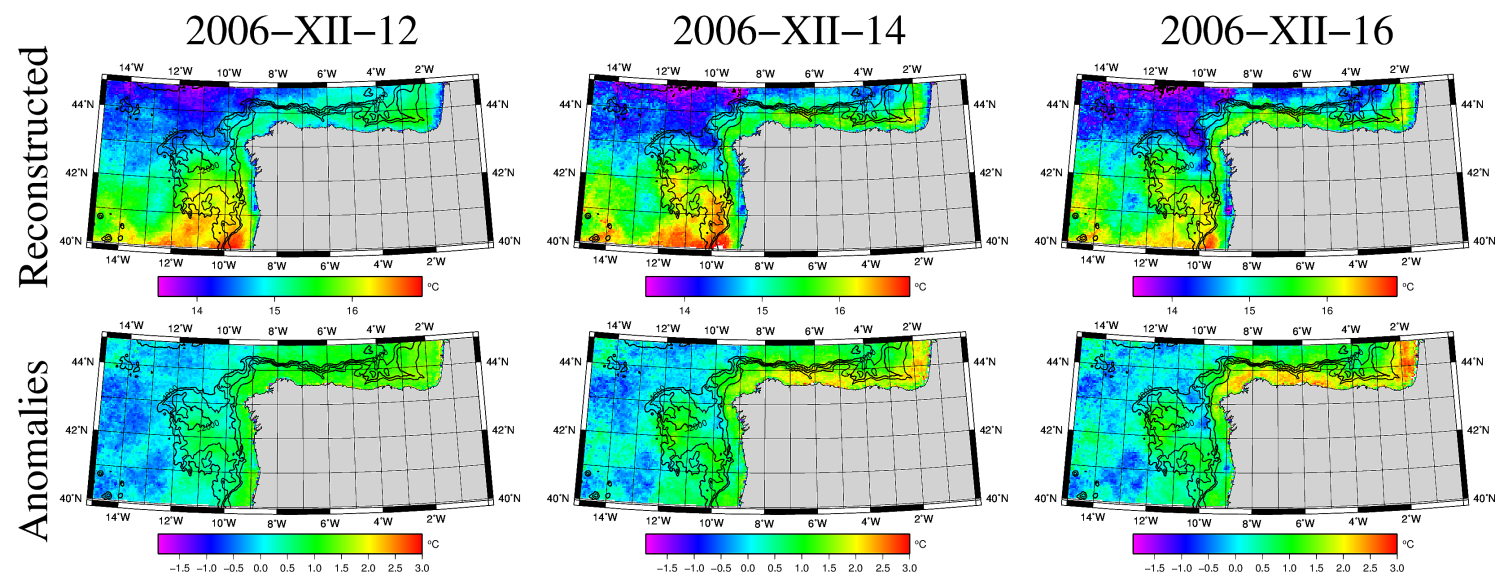

Fig. 5. Reconstructed SST fields (top panels) and their related anomalies (bottom panels) for 12, 14 and 16 December 2006.

the IPC-Navidad signal, especially clear in the SST anomalies, over these five days. This result adds value to the reconstruction as such an intensification cannot be detected in the monthly averages used in previous studies (see last column of Table 2). It is also very difficult to detect it in the gappy SST images due to their high percentages of missing data.
Once the approximated shape of the IPC surface signal in SST anomalies has been introduced, the main wintertime SST variability mode and its relation with the IPC will be analysed. The determination of that mode will be based on a PCA of the SST anomalies. The results of such an analysis are very dependent upon the precise selection of the area. 
After checking different options (not shown), the best option for the purpose of capturing the IPC-Navidad variability was found to be the area constrained between the $2000 \mathrm{~m}$ isobath and the coast. This choice is also supported by both the shape of the anomaly patterns in Figs. 4 and 5 and by the fact that as the IPC is a slope-and-shelf current its surface signal is expected to be mainly located in that area.

The first empirical orthogonal function (EOF) obtained from the reconstructed Pathfinder 1981-2010 SST anomalies is shown in Fig. 6. The equivalent EOF of the 2002-2010 combined reconstruction was nearly identical and thus is not shown (coherence of both EOFs was nearly 1). The EOF pattern explains a $49 \%$ of the variance of the SST and it consists of a positive anomaly with values mainly in the $0.6-0.9^{\circ} \mathrm{C}$ range. It is strongest in the western Iberian coast; to the north and east it follows the $1000 \mathrm{~m}$ isobath as the coast changes its orientation, then east of $7^{\circ} \mathrm{W}$ it follows the $200 \mathrm{~m}$ isobath as it weakens and finally it is reinforced in the corner of the Bay and to the North along the French coast. The standardised principal component (PC), i.e. the time expansion series, related to the first EOF, is shown in Fig. 7. As in the case of Fig. 3 only wintertime months are shown and February to November switches are identified by vertical dashed lines. Red dots show the 1981-2010 first PC and the blue dots the 2002-2010 first PC.

The spatial shape of the EOF is consistent with the surface SST anomaly patterns being related to a well developed IPCNavidad event previously shown in Figs. 4 and 5. Although consistent with the shape of those anomalies, the spatial pattern does not show the stronger SST anomaly signal over the slope area, as might be expected. In order to check whether this was related to the inclusion of the over-shelf pixels, the PCA was repeated removing such pixels. The results (not shown) were almost identical to the ones given here, pointing to other reasons as responsible of this behaviour. Those could be the presence of part of the IPC-Navidad signal in the climatology used to deduce the SST anomalies or the spatial SST asymmetry expected for IPC-Navidad and nonIPC-Navidad conditions. Assuming that the EOF is related to a well developed IPC in terms of surface temperature signal, then the corresponding PC would be giving the approximate time evolution of the surface signal of the IPC during the winters over almost three decades. If strong enough evidence is collected to confirm such relation, the time series shown in Fig. 7 would be the longest estimation of the time evolution of the surface signal of the IPC. It would also be the estimation having the highest sampling frequency. To test that hypothesis, the reconstruction of the IPC-Navidad occurrences will be described within the context of previous studies. Then, based on the WOD profiles, additional evidence will be given by means of the vertical structure and water mass properties related to the strongest occurrences and nonoccurrences of the IPC-Navidad in that series.

The surface signal of the IPC has been usually detected in the past in infrared satellite images. Along with these im-

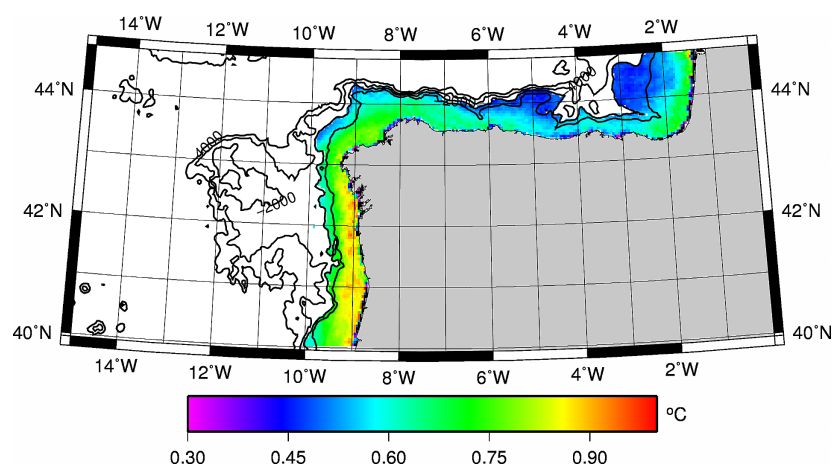

Fig. 6. First EOF of the PCA analysis of the 1981-2010 reconstructed SST dataset when only pixels with a related depth of less than $2000 \mathrm{~m}$ are taken into account. The $200 \mathrm{~m}$ depth contour is shown in addition to the contour depths shown in previous figures.

ages in situ cruise and station measurements (temperature, salinity, currents, etc.) and later satellite altimetry and related products have also gained increasing relevance in the study of the IPC itself. Both estimations of the winter interannual variability of the IPC and its surface signal on the yearly and monthly scales have also been derived based on infrared satellite images and in situ data. Table 2 summarises the documented detections of the IPC and its surface signal during the last decades showing the dates, the employed techniques and references of different studies. Based on the comparisons of these results, the hypothesis that the time series displayed in Fig. 7 represents the surface signal of the IPC-Navidad will be checked in the following paragraphs.

The number of previous works to which our time series will be compared is great. In addition, these works are related to the IPC-Navidad surface signal, in some cases (i.e. in the inner Bay) to the surface signal of the IPC in the western Iberian area, and to the IPC itself in other cases. Finally, individual detections of those three can be found, as well as estimations of their interannual variability. Accordingly, some caution is needed when making the comparison. In order to make it as clear as possible, the comparison is structured so that first our time series is compared with reported detections and variability estimations of the IPC-Navidad surface signal. As our time series deals with this process, the best accordances are expected in this case. Then, our time series will be compared with the detections and variability estimations of the surface signal of the IPC in the western Iberian area. Such detections can involve or not a signal in the inner Bay, so discrepancies are expected in some cases. Finally, the time series will be compared with the detections and variability estimations of the IPC itself, and not only its surface signal. Once again, as our series describes the evolution of the surface signal of the current, discrepancies are expected. A final word is necessary before the comparison is conducted in the following. As the number of previous works to which our time series will be compared to is great, and their content 
Table 2. The references, dates and the employed technique for the documented IPC and IPC-Navidad detections during the last decades. Only detections from the months taken into account in this study are shown (Nov-Dec-Jan-Feb). A brief description is given whenever the number of dates is very high. Studies that do not take into account the inner part of the Bay of Biscay, i.e. limited to the western or north-western Iberian coasts are identified by the WI acronym (IPC cases, not IPC-Navidad).

\begin{tabular}{|c|c|c|c|}
\hline Reference & Dates (DD/MM/YYYY) & Method & Time evolution \\
\hline Pingree and Le Cann (1989) & 28/12/1983, 31/01/1989 & Infrared (ind. images) & $*$ \\
\hline Frouin et al. (1990) & $\begin{array}{l}06(30) / 11 / 1983,04(27)(29) / 12 / 1983 \\
01 / 01 / 1984\end{array}$ & Infrared (ind. images) & $*$ \\
\hline Pingree and Le Cann (1990) & 28/12/1983, 28/12/1989, 01(13)/01/1990 & Infrared (ind. images) & $*$ \\
\hline Haynes and Barton (1990) & $11 / 01 / 1988$ & $\begin{array}{l}\text { Infrared (ind. images) } \\
\text { (WI) }\end{array}$ & $*$ \\
\hline Pingree and Le Cann (1992a) & 28/12/1983, 28/12/1989, 31/01/1989 & Infrared (ind. images) & $\begin{array}{l}\text { 1984-1991 } \\
\text { Dec-Jan-Feb monthly }\end{array}$ \\
\hline Pingree and Le Cann (1992b) & 28/12/1983, 28/12/1989, 04(12)/01/1990 & Infrared (ind. images) & $*$ \\
\hline Pingree (1994) & $\begin{array}{l}\text { Subsurface temperatures: } \\
\text { 1988-1989 (mooring 118) } \\
\text { 1990-1991 (mooring 129) } \\
\text { Surface temperature (ICES) }\end{array}$ & $\begin{array}{l}\text { Satellite (monthly) } \\
\text { In situ }\end{array}$ & $\begin{array}{l}\text { 1967-1993 Januaries } \\
\text { (satellite and ICES) } \\
\text { 1988-1989 \& } \\
\text { 1990-1991 (moorings) }\end{array}$ \\
\hline Garcia-Soto et al. (2002) & $\begin{array}{l}\text { 17/01/1979, 17/01/1982, 28/01/1983, } \\
\text { 09/01/1986, 11(19)/01/1988, 29/01/1989, } \\
\text { 12/01/1990, 12/01/1991, 06/01/1992, } \\
\text { 22/01/1993, 18/01/1994, 13/01/1995, } \\
\text { 18/01/1996, 08(12)(19)(21)(22)/01/1998 }\end{array}$ & $\begin{array}{l}\text { Infrared (ind. images) } \\
\text { Satellite (monthly) } \\
\text { In situ }\end{array}$ & $\begin{array}{l}\text { 1967-1993 Januaries } \\
\text { (satellite and ICES) } \\
\text { 1979-2000 Januaries } \\
\text { (missing 1980, 1981 } \\
\text { and 1985) }\end{array}$ \\
\hline Peliz et al. (2003) & 28/01/1997, 25/02/1998, 09(16)/01/2002 & $\begin{array}{l}\text { Infrared (ind. images) } \\
\text { (WI) }\end{array}$ & $*$ \\
\hline Garcia-Soto (2004) & $\begin{array}{l}\text { 26/11/2002, 13/01/2003 } \\
\text { and Alt.: } 18 / 12 / 2002\end{array}$ & $\begin{array}{l}\text { Infrared (ind. images) } \\
\text { and Altimetry }\end{array}$ & 1979-2003 Januaries \\
\hline Peliz et al. (2005) & $\begin{array}{l}\text { 28/01/1997, 09/02/1997, 25/02/1998, } \\
09(16) / 01 / 2002\end{array}$ & $\begin{array}{l}\text { Infrared (ind. images) } \\
\text { (WI) }\end{array}$ & $\begin{array}{l}\text { WI zonal SST gradient } \\
\text { 1985-2001 Jan-Feb }\end{array}$ \\
\hline Llope et al. (2006) & $T / S$ profile per winter (Dec, Jan or Feb) & In Situ (WI) & $\begin{array}{l}\text { 1992-2003 } \\
\text { yearly winter mean }\end{array}$ \\
\hline Torres and Barton (2006) & $\begin{array}{l}31-06 / 10-11 / 1999 \\
\text { and Cruise: } 13-7 / 10-11 / 1999\end{array}$ & $\begin{array}{l}\text { Infrared (weekly) } \\
\text { and in situ (WI) }\end{array}$ & $*$ \\
\hline Le Cann and Serpette (2009) & $\begin{array}{l}\text { 29/11/2006, 14/12/2006 } \\
\text { and Cruise: } 6-11 / 11 / 2006\end{array}$ & $\begin{array}{l}\text { Infrared (ind. images) } \\
\text { and in situ }\end{array}$ & 1995-2006 yearly \\
\hline deCastro et al. (2011) & 1985-2006 Januaries & Infrared (monthly) & 1985-2006 Januaries \\
\hline Herbert et al. (2011) & $\begin{array}{l}\text { SST: } 20 / 01 / 2004,31 / 01 / 2004 \text {, } \\
01 / 02 / 2004 \\
\text { and Alt.: } 12-18 / 01 / 2004,1-7 / 02 / 2004 \text {, } \\
\text { 25-01/10-11/2004 }\end{array}$ & $\begin{array}{l}\text { Infrared } \\
\text { and altimetry }\end{array}$ & * \\
\hline Le Hénaff et al. (2011) & $\begin{array}{l}1992-2002 \text { Dec/Jan and Jan/Feb SST } \\
\text { and Topex/Poseidon track } 137\end{array}$ & $\begin{array}{l}\text { Infrared } \\
\text { and altimetry }\end{array}$ & $\begin{array}{l}\text { 1992-2002 } \\
\text { (2 months per winter) }\end{array}$ \\
\hline Garcia-Soto and Pingree (2012) & $\begin{array}{l}01-31 / 01 / 1990,21 / 12 / 2000,12 / 01 / 2001 \\
13 / 01 / 2003,26 / 11 / 2006,14(28) / 12 / 2006 \\
09 / 01 / 2007,14 / 02 / 2007,25 / 12 / 2009 \\
03 / 02 / 2010\end{array}$ & $\begin{array}{l}\text { Infrared } \\
\text { (ind. images, monthly) } \\
\text { ERSST v3b (monthly) }\end{array}$ & $\begin{array}{l}\text { 1979-2010 } \\
\text { (monthly) }\end{array}$ \\
\hline
\end{tabular}


heterogeneous, the comparison will be more qualitative than quantitative. This means that it will be conducted visually by comparing the value of our time series (e.g. positive/negative or strong/weak) with the corresponding result in the previous works; hence, without giving a quantitative value of the degree of agreement or disagreement.

Starting with the detections of the IPC-Navidad based on individual SST images, all found in Frouin et al. (1990), Pingree and Le Cann (1989, 1990, 1992a,b), Garcia-Soto (2004) and Le Cann and Serpette (2009) are confirmed by our IPCNavidad signal estimation. For the case of the images shown or referenced by Garcia-Soto et al. (2002) most of the occurrences and non-occurrences are confirmed with the exceptions of January 1986, 1991, 1992 and 1994, when weak events are described by those authors. The comparison with the images given in Garcia-Soto and Pingree (2012) also shows a high level of coherence. However, a discrepancy occurs in the 2000/2001 transition and it will be described in order to give a detailed example of at least one discrepancy. Images for 21/12/2000 and 12/01/2001 in Garcia-Soto and Pingree (2012) show an IPC-Navidad like structure. The nearest (in time) reconstructed image in our series $(23 / 12 / 2000$; $21 / 12 / 2000$ was not reconstructed due to the low percentage of available data) does show such a structure and yields a positive value in the PC time series. In the case of 12/01/2001, our corresponding reconstructed image also shows a weak IPC-Navidad like structure but the time series fails to capture it, probably because it is a weak event. The SST images in Herbert et al. (2011) showing the clearest IPC signal evidence for the end of January and the beginning of February 2004 are confirmed by our series. The result is similar to that obtained for the comparison with individual images from Le Hénaff et al. (2011), where clearest 1993, 1996 and 1998 cases are confirmed. The signal is not very clear for the case of January 2001 (the number of reconstructed days in that month is small). Concerning the estimations of the interannual variability of the IPC and its surface signal, the very first estimation was obtained by Pingree and Le Cann (1992a) for the 1984-1991 period (3 values per winter). Taking into account that the anomalies from their series were relative to the 1985 values, and considering accordingly the anomalies from our series with respect to the 1985 values, a good agreement is observed between both series. A second estimation for the Januaries in the 1967-1993 period can be found in Pingree (1994), where January ranges of the SST in the northern Spanish coast are shown based in ICES (International Council for the Exploration of the Sea) and satellite data. The comparison with this estimation shows a very good agreement for the shared time range, with the possible exception of 1992, although the comparison has to be done with care as an anomaly time series is being compared with a SST range time series. Based on January images Garcia-Soto et al. (2002) and Garcia-Soto (2004) make a classification of IPCNavidad and non-IPC-Navidad years in the 1979-2004 period. Of the January IPC-Navidad events described by these authors, only the one in January 2001 of our series seems to disagree. However, the number of reconstructed days in our series is very limited in that year. With respect to the relative strength of the IPC-Navidad episodes over the 19792004 period, year transitions from 1989/1990, 1995/1996, $1997 / 1998$ and 2002/2003 are considered the strongest by these authors. All of them are among the strongest in our series. The most recent estimation of the long-term variability of the IPC-Navidad signal is shown in Garcia-Soto and Pingree (2012), where the monthly evolution of the SST anomalies off the Iberian margin are given for the 1950-2010 period based on the ERSST v $3 \mathrm{~b}$ data. The number of data to be compared in this case is great, but as the agreement among the time series is good in general, no further detail will be given in this case to keep this comparison simple.

In the case of SST images used in studies only focused on the western Iberian coast (WI in Table 2), those in Haynes and Barton (1990) and Torres and Barton (2006) find confirmation in our series (agreement with an early development in the case of the second), while those in Peliz et al. (2003) and Peliz et al. (2005) find both agreements and disagreements. This is not surprising, however, as the shape of the EOF in Fig. 6 indicates that the series in Fig. 7 would represent IPCNavidad episodes (i.e. entering the Bay of Biscay), which do not necessarily have to develop even if a surface signal of the IPC is observed in the western Iberian area. Regarding the interannual variability estimations over this area, yearly series given in Peliz et al. (2005) and deCastro et al. (2011) are methodologically similar as both are based on the zonal SST gradient off the western Iberian coast, but for different months: the first one for December-January means and the second one only for Januaries. A general good agreement is obtained for both series, except for 1997 and 1999 in Peliz et al. (2005) and 1991 and 1995 in deCastro et al. (2011). Comparing together the series from those two studies with our series, it appears that the year 1999 shows the most remarkable differences, although other smaller differences also occur, both with our series but also among these two series themselves.

Finally, our time series will be compared with the estimations of the IPC itself, not its surface signal. Based in two mooring records (at depths of 210 and $250 \mathrm{~m}$ ) in the northern Spanish coast, Pingree (1994) shows the development of two IPC events, a strong one in 1988/1989 with a maximum in late January, and a weak one in 1990/1991 with a maximum in mid January. The first one finds a good correspondence with our series, while the second one does not. For the case of the estimations based on in situ cruise and station measurements, a good agreement is found for Torres and Barton (2006) and Le Cann and Serpette (2009). Regarding the interannual variability, in the case of the series of the vertical $T / S$ (temperature/salinity) profile estimated by Llope et al. (2006), the agreement with temperature profiles is correct for most of the years, although the comparison is not clear for 1998/1999 and 1999/2000 and a disagreement is detected 

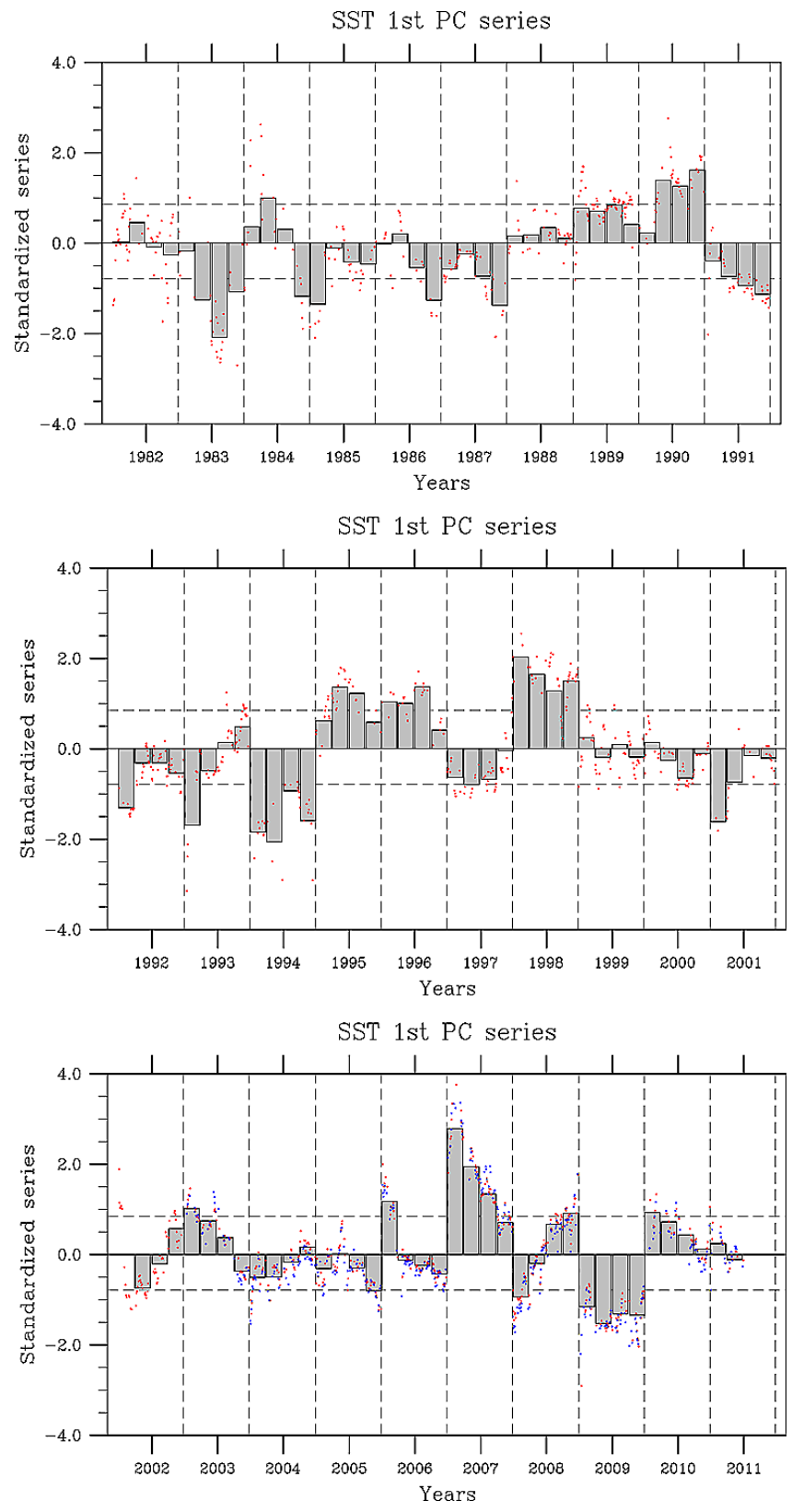

Fig. 7. The PC related to the EOF shown in Fig. 6. Vertical dashed lines indicate jumps from the end of February to the beginning of November of the same year. Red points are related to the PC deduced from the 1981-2010 reconstructed SST PCA and the blue ones to the 2002-2010 reconstruction. Grey vertical bars give the mean monthly values of the red dot values, while the horizontal dashed lines the 20th and the 80th percentiles of the 3 decade daily time series.

for $2002 / 2003$. The comparison with the IPC-Navidad occurrence series of Le Hénaff et al. (2011), i.e. the monthly SST and geostrophic current anomaly indices, shows that the two main episodes in 1995/1996 and 1997/1998 described by these authors are consistent with our estimations for these years. For the rest of the years the agreement is uneven, especially with the current anomaly index.

The previous comparison shows a good agreement in general between our IPC-Navidad time series and the previous works, specially, and as expected, for the case of the IPCNavidad surface signal detections. For the western Iberian detections of the surface signal of the IPC and the results related to the IPC itself, the comparison does not show such a clear image but it can also be considered satisfactory if it is taken into account that our series is describing IPC-Navidad occurrences.

In the following, additional confirmation of the validity of our IPC-Navidad series will be obtained based on the combination of its extremal properties and the WOD data. The two dashed horizontal lines in Fig. 7 show the 80th and 20th percentiles of the 1981-2010 PC series. Days in the time series above the 80th percentile are those related to the most developed IPC-Navidad events according to the PC and will be denoted P80. Meanwhile, those below the 20th percentile represent the periods without, or with very weak, poleward flow and will be denoted P20. The properties related to these two groups will be used as indicative of the conditions related to well developed IPC-Navidad events and to their opposite conditions in terms of the PCA mode. For each set of days, P80 and P20, the available WOD vertical temperature and salinity profile data were selected for each of the 4 area boxes (I, II, III, IV) and the corresponding temperature and salinity means were computed for each depth. Torres and Barton (2006) found that the major poleward signal was located off the slope (characterised by the $200 \mathrm{~m}$ isobath), so only vertical profiles located off the slope will be considered. To include a larger number of profiles for each case, and as the timescale related to the onset of poleward flowing surface warm anomalies has been estimated to be around a 5-10 day period (Torres and Barton, 2006), the P80 and P20 day sets were expanded adding the previous and subsequent 5 days to each date in the sets. Figure 8 shows the mean vertical temperature and salinity profiles denoted P80-Temp (solid red), P20-Temp (dashed red), P80-Sal (solid blue) and P20-Sal (dashed blue). For depths where the temperature (salinity) means P80-Temp (P80-Sal) and P20-Temp (P20-Sal) reject the null hypothesis that they belong to the same sample mean by more than a $95 \%$ confidence given by a $t$ test (Wilks, 2006) a dot is added in the profile. The number of individual profiles taken into account in each mean is also shown by each corresponding label. Finally, it has to be mentioned that Fig. 8 shows homogeneous depth, temperature and salinity scales, so that shallow layers characterised by higher variability can be effectively compared.

Vertical temperature profiles (Fig. 8) in the areas close to the Portuguese and Spanish coasts (I, II, III) show the presence of significantly warmer waters in the first $100-200 \mathrm{~m}$ for the P80 set of days compared to those of the P20 set. In the case of the P80 set, the surface temperature value is $16.4{ }^{\circ} \mathrm{C}$ for area I and approximately a degree colder for areas II and 


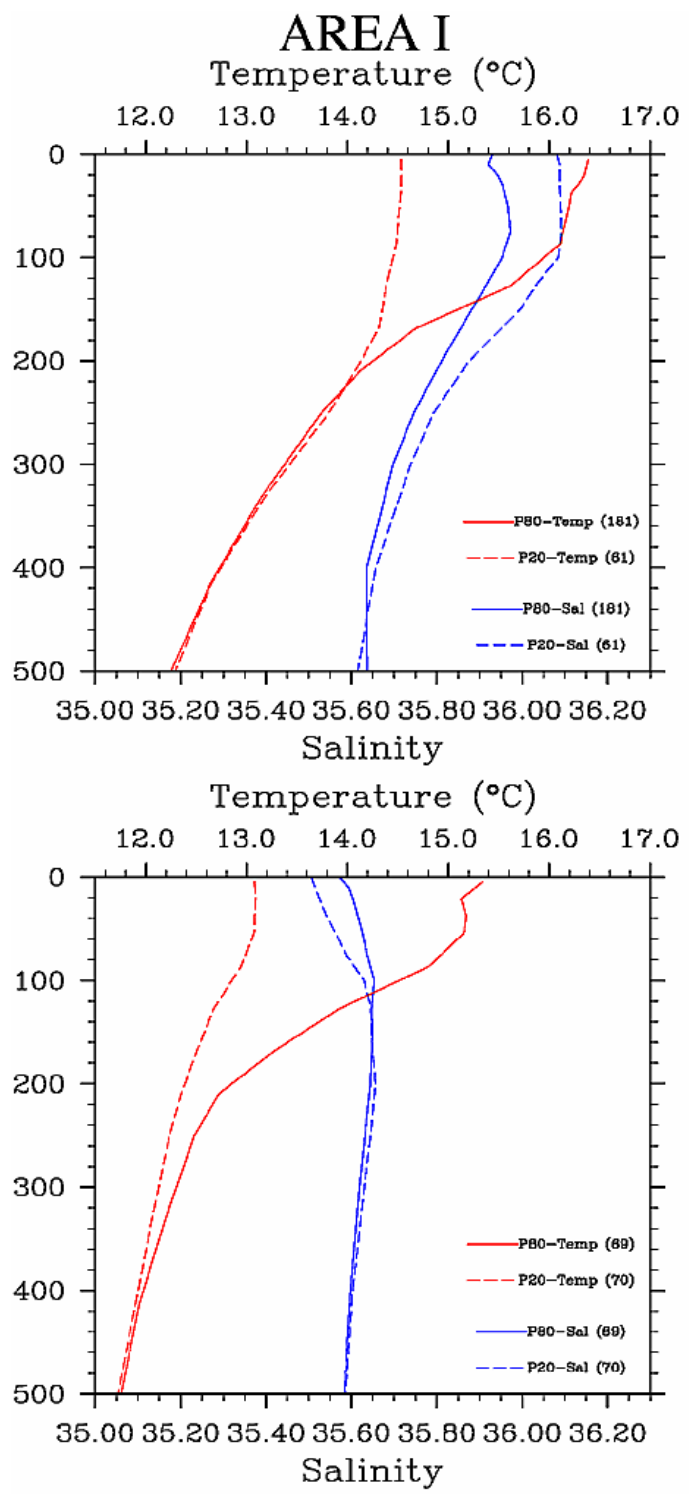

AREA III

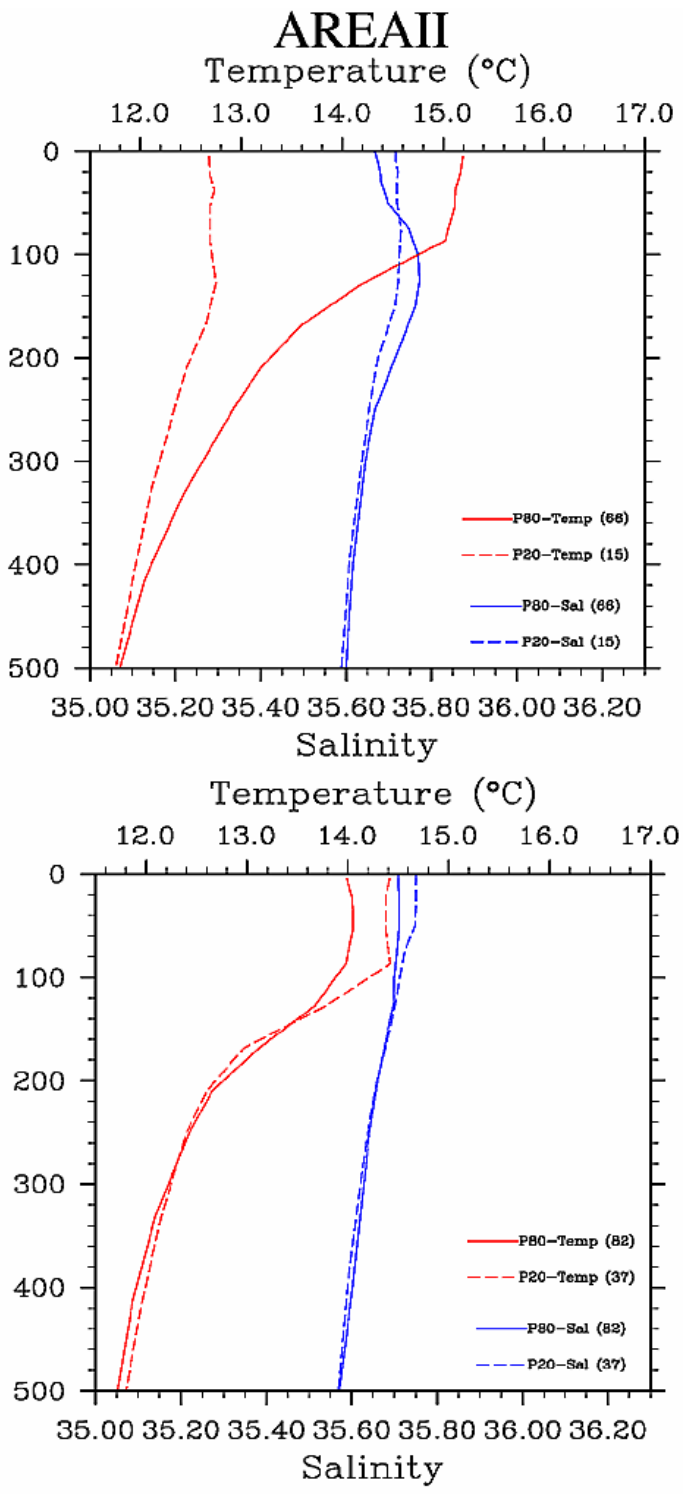

AREA IV

Fig. 8. Mean vertical temperature (red) and salinity (blue) composite profiles related to the P80 (solid lines) and P20 (dashed lines) day sets. Profiles for the \pm 5 days of each day in the P80 and P20 day sets are taken into account. The numbers of vertical profiles involved in each case is given in parenthesis by its corresponding label. Each of the 4 figures belongs to the corresponding area shown in Fig. 1.

III. Following the path of the poleward flow, the same progressive cooling is observed also for the P80 set for temperatures at $50 \mathrm{~m}\left(16.2,15.1\right.$ and $\left.14.8^{\circ} \mathrm{C}\right)$ and $100 \mathrm{~m}(14.7,13.6$ and $13.3^{\circ} \mathrm{C}$ ) depths, with a $1.1^{\circ} \mathrm{C}$ cooling from area I to area II and a $0.3{ }^{\circ} \mathrm{C}$ one from area II to area III. The salinity pattern is more complicated than the temperature in each area, especially because enhanced salinity values are observed for P20 in area I, which is not the case for areas II and III. In the case of the P80 salinities, subsurface maxima are found for areas I and II at 75 (> 35.95) and $125 \mathrm{~m}$ (> 35.75) depths respectively. The open ocean area IV was introduced to check whether any influence of the IPC could be detected there (en- tire coverage of area IV is detailed in the caption of Fig. 1). The vertical profiles of the open ocean area IV indicate no major difference between the P80 and P20 sets, meaning that the poleward flow is confined to areas near the slope.

The $T / S$ characteristics of the layer from the sea surface to $500 \mathrm{~m}$ depth in the WOD data are shown in Fig. 9 for the same 4 areas, including also over-shelf (depth $<200 \mathrm{~m}$ ) profiles. The temperature and salinity scales are the same for all 4 areas, and additional data from deeper levels have been included, so as to be able to compare different patterns at the salinity minimum corresponding to ENACW (Eastern North Atlantic Central Water). Temperature and salinity pairs 

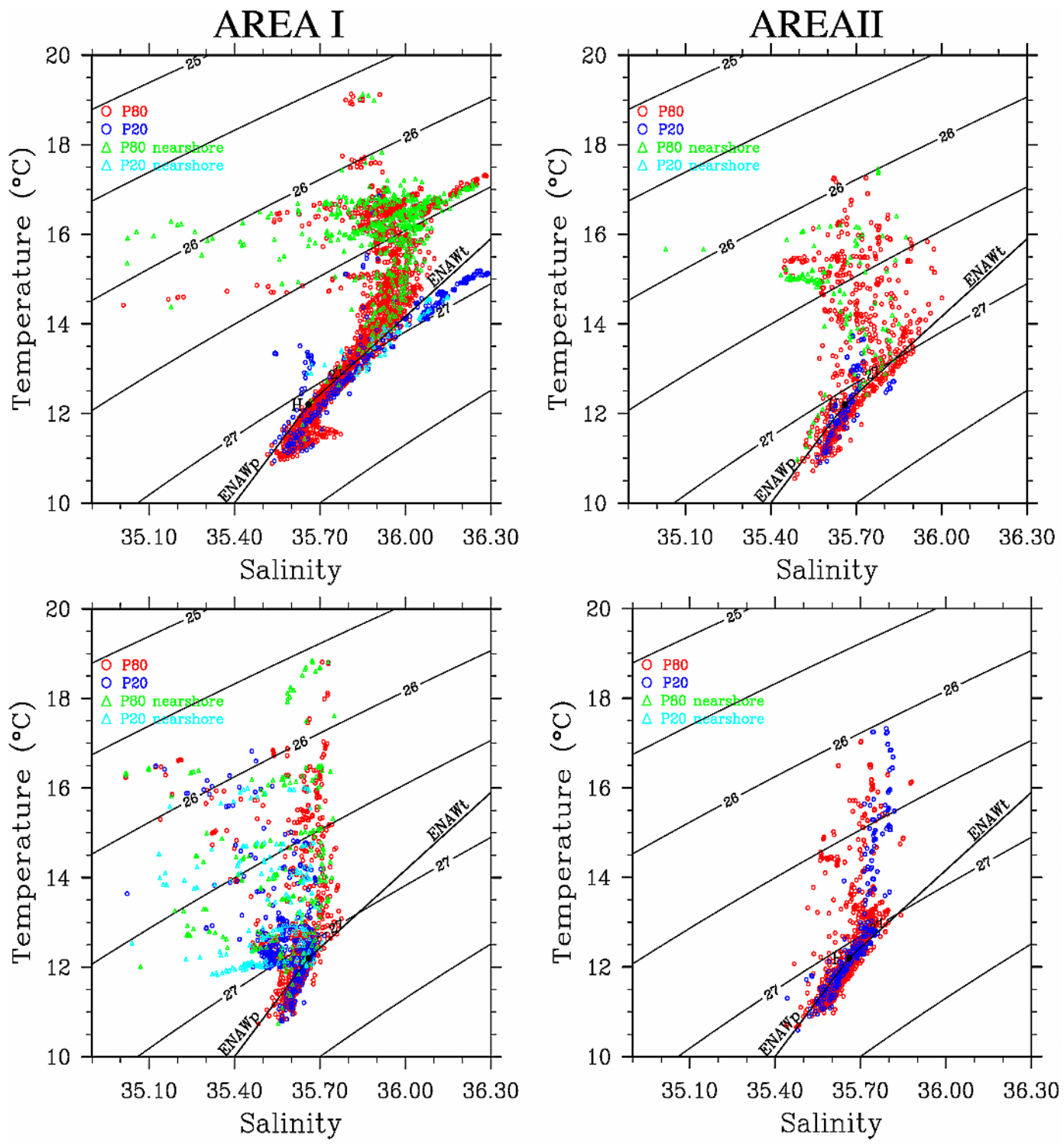

AREA III

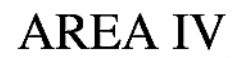

Fig. 9. As Fig. 8 but for the $T / S$ diagrams instead of the vertical profiles (also including the 300-500 m depth range). The profiles related to shallow $(<200 \mathrm{~m}$, triangles) and deeper waters (circles) are plotted separately, so that the red and green markers are related to the P80 set and the dark and light blue ones to the P20 set. $\mathrm{ENAW}_{\mathrm{P}}$ and $\mathrm{ENAW}_{\mathrm{T}}$ definition lines, and also their crossing point $(H)$, are indicated.

belonging to the P80 and P20 sets are represented by red and blue circles, respectively, and by green and light blue triangles for over-shelf values. The definition curves of the two varieties of the Eastern North Atlantic Water (ENAW) found in the area, the colder $\mathrm{ENAW}_{\mathrm{P}}$ (subpolar) and the warmer ENAW $_{\mathrm{T}}$ (subtropical), are shown in the $T / S$ diagrams. The definitions of these varieties, as will be used here, can be found in Ríos et al. (1992) for example, and have already been used in IPC related studies in the area (Llope et al., 2006; Torres and Barton, 2006). These straight segments in a $T / S$ diagram correspond to simple mixing processes and transports along neutral or approximately isopycnal levels.
The temperature and salinity values in Fig. 9 are among previous values described for the study area by McCartney and Talley (1982), Ríos et al. (1992), Llope et al. (2006), and Torres and Barton (2006), among others.

The poleward flow signature (warmer red and green symbols) is most clearly seen in area I, but is also evident in areas II and III. A modification of the water mass properties is observed following the IPC evolution path from area I to area III, with a progressive decrease in the proportion of $\mathrm{ENAW}_{\mathrm{T}}$. A progressive decrease in the salinity is also observed following that path from approximately 35.9 in area I to 35.6 in area III. Although that salinity change must not be considered 
as instantaneous, but rather as a time integrated change in the water column, a change of 0.3 over a $200 \mathrm{~m}$ water column is important. The order of magnitude of this balance was deduced by Pérez et al. (2000) using data and estimation by Rogers and Van Loon (1979) and Reverdin et al. (1994). The order of magnitude of their and our balances are similar, when taking into account both evaporation/precipitation and river run-off. The eastward evolution of the $T / S$ characteristics on the northern coast (area II to III) is also consistent with those found by Llope et al. (2006) and Le Cann and Serpette (2009). Llope et al. (2006) also showed the transition from non-IPC to IPC conditions in terms of $T / S$ relationships in October-November 1999, which is fairly consistent with the differences between the P80 and P20 cases shown here. The IPC related sub-surface salinity maximum is most clearly detected in the case of area II. Some evidence of local water mass property modification in the corner of the Bay of Biscay (in area III) can be detected for both the P20 and P80 sets (around $12.5^{\circ} \mathrm{C}$ and 35.55 ), but specially for the former. In the case of area IV similar results are obtained for both sets, with a possible salinification for the P20 set. No water mass of ENAW $\mathrm{T}$ origin seems to reach this area in any of the cases.

Through this section, an estimation of the time evolution of well developed IPC-Navidad events, as well as the related SST structure, were obtained in terms of the first variability mode of a PCA analysis of the reconstructed SST. The validity of the time evolution series was then checked by comparison with all estimations that were available up to now and a good correspondence in most of the cases could be found. In addition, further confirmation of that validity was obtained based on vertical temperature and salinity distributions and $T / S$ diagrams. In the following, the estimated and validated time series will be used to analyse the mechanisms that control the variability of the surface signal of the IPC.

\subsection{Insights on the Iberian Poleward Current variability mechanisms}

Previous studies on the interannual variability of the IPC and IPC-Navidad have mainly focused on the NAO teleconnection pattern (i.e. Garcia-Soto et al., 2002; Garcia-Soto, 2004; Llope et al., 2006; Le Cann and Serpette, 2009; Le Hénaff et al., 2011), although some evidence for the relation with the EA/WR pattern has also been found (deCastro et al., 2011). All these studies describe lagged integrated relations, among which the relation of January IPC and IPC-Navidad occurrences and the negative mean November-December NAO index is the most recurrent (IPC-J NAO-ND). The relations with the main monthly Northern Hemisphere teleconnection indices were studied here as well. A monthly version of the daily frequency IPC-Navidad time series (Fig. 7, grey bars) was used for that purpose. The relationship at daily timescales will be later analysed. Standardised monthly series related to the NAO, eastern Atlantic (EA), EA/WR,
Polar/Eurasia (POL) and Scandinavia (SCA) teleconnection patterns were obtained from the Climate Prediction Center (CPC at NCEP) (http://www.cpc.ncep.noaa.gov). Synchronous and lagged correlations were checked, allowing also time integrated combinations. The significance level for meaningful correlations was set at $99 \%$ (estimated by a Monte Carlo test).

Table 3 shows the significant correlations between the monthly IPC-Navidad time series and some of the teleconnection patterns of the Northern Hemisphere. Relationships are observed with four teleconnection patterns (NAO, EA, EA/WR, SCA), being most recurrent for the case of the NAO, but no preferential relationship is found for any of them. Due to this fact, the forthcoming analysis will not deal with relationships with any of the Northern Hemisphere teleconnection patterns. Instead, the extremal values of the daily frequency IPC-Navidad time series and a combination of several atmospheric and ocean surface variables will be used in a composite analysis in order to identify the patterns that drive the variability of the IPC-Navidad. This procedure will allow us a more general characterisation of the atmospheric circulation anomalies related to the Navidad-IPC as the analysis will not be limited only to the most common teleconnection patterns.

The extremes of daily time series of the IPC-Navidad occurrence have already been used to infer the water mass characteristics related to these extremes. The same P80 and P20 day sets will also be used to identify the atmospheric circulation anomaly patterns that occur prior to the strongest anomalies of occurrences and non-occurrences of the IPC-Navidad. Assuming that time lagged relations may well occur, lagged versions of P80 and P20 are consequently created by displacing the dates by a given lag. Accordingly, two composite patterns for each variable (from ERA-Interim or AVISO datasets) will be computed by averaging the spatial fields of the variable over the dates with extreme IPC-Navidad, one for the positive (related to P80) and another for the negative (related to P20) cases. Then the negative composite is subtracted to the positive one $\left(C_{\mathrm{P}-\mathrm{N}}=C_{\mathrm{P}}-C_{\mathrm{N}}\right)$, and finally, a $t$ test of significance of this difference is performed at every grid cell and values are only shown on locations where the null hypothesis of equal means is rejected at the $95 \%$ confidence level.

This methodology was applied to eight variables whose characteristics and spatial coverage were described in Sect. 2.1: the $500 \mathrm{hPa}$ level geopotential height anomalies from the ERA-Interim reanalysis and the approximated location of the storm track estimated from filtered geopotential height anomalies; the anomalies of the surface pressure; the surface turbulent fluxes; the surface wind stress taken from the reanalysis together with the curl of those windstress anomalies; and finally the sea level anomalies and related geostrophic current anomalies obtained from AVISO. The time spans for the ERA-Interim and AVISO variables are 1981-2010 and 1992-2010 respectively. Figure 10 shows 
Table 3. Significant correlations (99\% level) between the monthly IPC-Navidad time series and the Northern Hemisphere teleconnection patterns (TP). Significant correlations are observed for the NAO, EA, EA/WR and SCA patterns; and for different combinations of September $(\mathrm{S})$, October $(\mathrm{O})$, November $(\mathrm{N})$, December (D), January $(\mathrm{J})$ and February $(\mathrm{F})$ months. Correlations are given in parenthesis.

\begin{tabular}{cccccc}
\hline TP & \multicolumn{5}{c}{ Navidad-IPC } \\
\cline { 2 - 6 } & NDFJ & N & D & J & F \\
\hline NAO & ONDJ (-0.29) & ON $(-0.57)$ & ON $(-0.49)$ & ON $(-0.49)$ & \\
EA & SOND (-0.27) & NDJF (0.28) & D $(0.51)$ & & \\
EA/WR & & & ND $(0.48)$ & \\
SCA & & & & F $(-0.57)$ \\
\hline
\end{tabular}

the resulting $C_{\mathrm{P}-\mathrm{N}}$ (composite) patterns, displaying pixels in which the differences in the mean were statistically significant (white pixels and missing arrows or contours where not). The left and right columns show the results for the $0-15$ and 15-30 day lag spans, respectively. Identical results were also obtained for the 30-45, 45-60, 60-75, and 75-90 day lag spans. Figure 10a $(Z)$ displays the difference patterns $C_{\mathrm{P}-\mathrm{N}}$ for the $500 \mathrm{hPa}$ height anomalies (black contours) and the red and blue contours represent the $C_{\mathrm{P}}$ and for $C_{\mathrm{N}}$, respectively. The approximated location of the storm track is represented by the colour scale. Figure 10b (SURFACE) shows the patterns for the surface pressure (grey contours), wind stress (arrows) and turbulent fluxes (colour scale) together, and Fig. 10c (SLA) those for the sea level anomaly. Finally, Fig. 10d shows the results for both the sea level anomaly (colour scale) and geostrophic current anomaly patterns (arrows), and also those of the wind-stress curl $\left(\mathrm{Nm}^{-3}\right)$ (blue contours for positive values and white ones for negatives), for the Bay of Biscay area.

The composite results for the atmospheric $500 \mathrm{hPa}$ level in Fig. 10a show that there are distinct circulation schemes associated with the positive and negative composites, observable both in the location of the storm track and the $500 \mathrm{hPa}$ heights. The location of the storm track, for both the 0-15 and 15-30 day lag ranges, is shifted southwestward in the case of $C_{\mathrm{P}}$ with respect to $C_{\mathrm{N}}$, as evidenced by the positive and negative values in those areas (colour scale). The red isolines displaying $500 \mathrm{hPa}$ height composite for the P80 set are shifted southward with respect to the P20 composite, with the exception of the easternmost area where the opposite is observed. Those displacements are summarised by the westeast dipole in the difference pattern (black). As the time lag grows in time, the difference pattern of the storm track location is slightly reinforced and the positive difference area of the $500 \mathrm{hPa}$ height is also slightly shifted northward. The results for the 30-45, 45-60, 60-75, and 75-90 day lag ranges (not shown) indicated a progressive reinforcement of the south-west positive value area (maximum for 45-60 day lag range) coincident with a progressive weakening of the negative value areas. This possibly indicates a faster weakening of the P20 pattern compared to the P80 pattern. However, significant differences are observed for most of the locations up to the 75-90 day lags. Meanwhile, the differences in the $500 \mathrm{hPa}$ heights are less persistent and shrink faster with increasing lags.

The composite patterns $\left(C_{\mathrm{P}-\mathrm{N}}\right)$ of the anomalies of pressure, turbulent flux and wind stress from ERA-Interim, in Fig. 10b, show mutually coherent patterns. The low pressure anomaly area is centred around $25^{\circ} \mathrm{W}, 50^{\circ} \mathrm{N}$; the wind patterns are coherent with the pressure patterns under the geostrophic approximation. The negative and positive anomalies of the turbulent flux are located in the westsouthwest and east-northeast sectors of the pressure anomaly, respectively, where advection of heat and humidity from more northerly or southerly locations occurs (Zorita et al., 1992). Note that the surface centre of action (maximum negative SLP anomaly area) is slightly shifted to the north-east with respect to the $500 \mathrm{hPa}$ pattern (maximum negative $Z$ anomaly area). At the surface, the pattern is also persistent for growing lags, with a progressive but slight weakening, and with statistically significant values up to the 60-75 day lag range.

SLA maps in Fig. 10c show a structure co-located and spatially coherent with that of the heat fluxes in the previous panels. Negative anomalies are located in the west-southwest sector and positive anomalies in the east-northeast sector. This pattern is noisy in the area of the Gulf Stream, and also to a lesser extent in the rest of the area in relation to the eddy signal. The overall SLA pattern points to an anticlockwise circulation anomaly, resulting in a weakening of the predominant anticyclonic circulation, i.e. a weakened North Atlantic gyre. Positive anomalies are located near the coast in the eastern Atlantic boundary over the continental shelf, especially from the western Iberian coast to well to the north of the British Isles, indicating the presence of poleward flowing geostrophic currents along most of the eastern Atlantic boundary. In fact, both the SLA and the related geostrophic currents are shown in Fig. 10d for the Bay of Biscay area. Close to the Iberian coast the currents follow the continental slope (200 m depth black contour), flowing northwards 

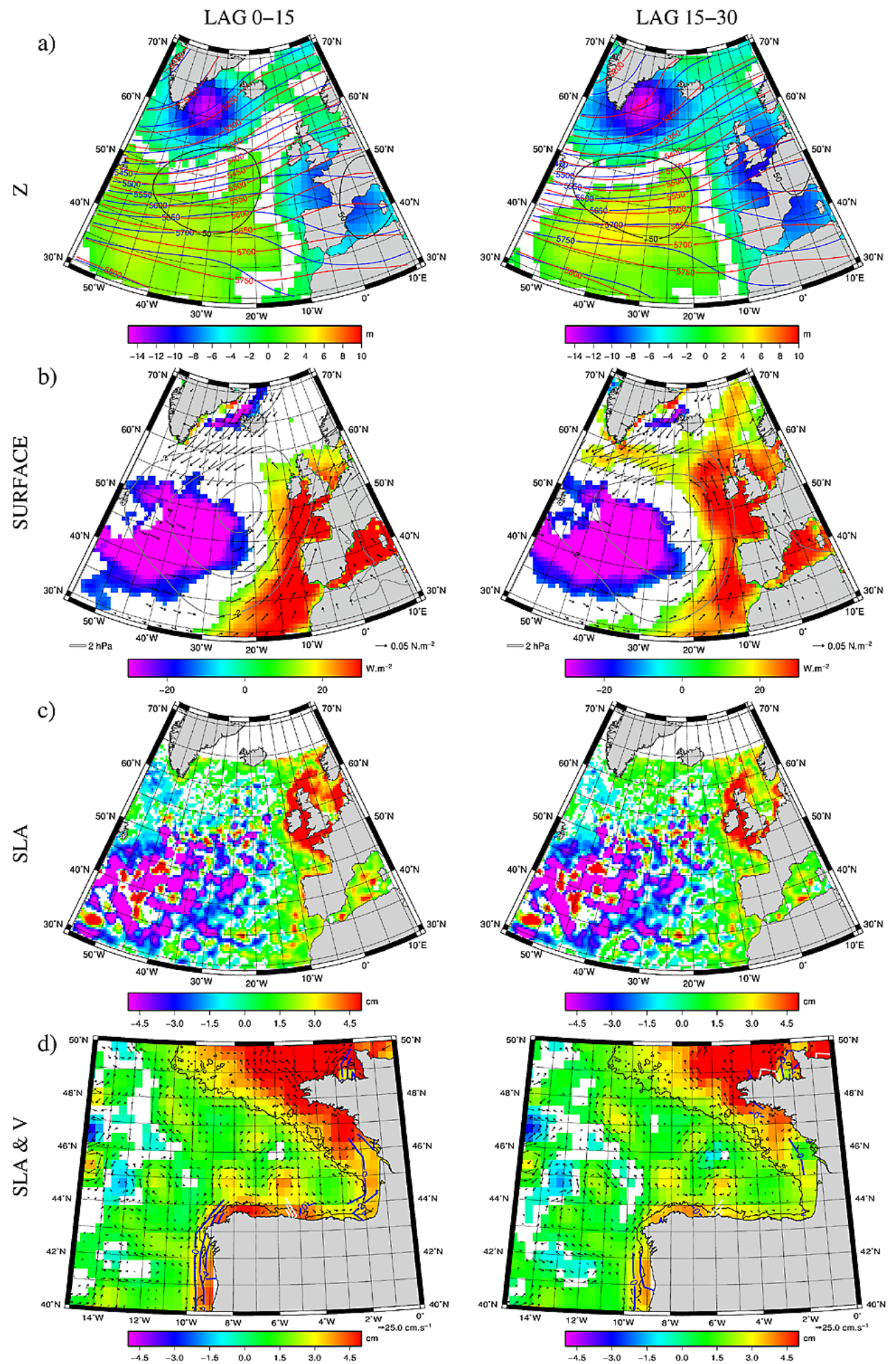

Fig. 10. Composite results based on the IPC-Navidad time series shown in Fig. 7. The analysed variables are the $500 \mathrm{hPa}$ geopotential height anomalies (a; red, blue and black contours), the estimated location of the storm track (a; colour scale), the surface pressure (b; grey contours), the surface turbulent fluxes (b; colour scale), the wind stress (b; arrows), the sea level anomalies (SLA) (c; colour scale) and the related current anomalies (d; arrows) and the curl of the wind stress (d; blue and white contours). The $200 \mathrm{~m}$ depth contour is shown in the figures in the bottom panels. Left and right panels correspond to the 0-15 and 15-30 day lag ranges. All variables are masked by the 95\% confidence mask built by means of a $t$ test on the difference of means. See the text for more details. 
along the the western coast, changing direction at the northwestern Iberian corner and then turning eastward with an apparent weakening in the Aviles Canyon $\left(6.32^{\circ} \mathrm{W}, 43.92^{\circ} \mathrm{N}\right)$ area. Further north, close to the French continental shelf the geostrophic currents also seem to follow the continental slope up to approximately $47^{\circ} \mathrm{N}$, drifting to the shallower waters near the Brittany coast first and then northwards. With increasing time lags, the altimetry composite shows a persistent behaviour maintaining significant values up to the 7590 day lag range variables. Although the weakening of the pattern is faster close to the Iberian coast, it declines slowly when the whole area is considered.

Additionally, two variables that have been described to modulate the development of IPC events were also considered: the positive wind-stress curl, which is related to the planetary and topographic $\beta$ effects, and the JEBAR effect, related to the poleward decline of steric sea level. The JEBAR effect is expected to develop at the western Iberian coast, but not at the northern coast, due to the relative orientations of the steric sea level gradient and the coast (Pingree and Le Cann, 1990). Such gradient was accordingly computed between two $1^{\circ}$ latitudinal bands of $2^{\circ}$ longitude width $\left(14-12^{\circ} \mathrm{W}\right)$ centred at $40^{\circ} \mathrm{N}$ and $43^{\circ} \mathrm{N}$ using the absolute dynamic topography obtained from AVISO. The P80 composites $\left(C_{\mathrm{P}}\right)$ of the gradient $(\mathrm{m} / \mathrm{m})$ for the $0-15$ and $15-$ 30 day lag show $\sim 2 \times 10^{-8}$ and $\sim 1 \times 10^{-8}$ values, while the rest of the positive lags yield approximately null values, indicating JEBAR favourable conditions in the western Iberian coast in the month previous to the major IPC-Navidad events. With regard to the $\beta$ effect, Le Cann and Serpette (2009) showed (their Fig. 9) that the climatological windstress curl was positive in the western Iberian coast, negative in western part of the northern coast and positive again in the eastern part, favouring the poleward flow in locations where it was positive. The winter climatological mean of the ERA-Interim wind stress showed a very similar spatial distribution (not shown). In addition to the climatological mean, the $C_{\mathrm{P}-\mathrm{N}}$ composite of the anomalies of the wind-stress curl was also computed. The corresponding contours are shown in Figure 10d, where significant positive and negative anomalies are denoted by blue and white contours respectively. The significant values near the coast form a pattern that is similar to that of the winter climatology, indicating a reinforcement of the long-term mean pattern in the P80 set.

A final set of composite patterns was derived to find out if the full set of coherent relations based on the local SST of the Bay of Biscay, and shown in the Fig. 10, also had a counterpart in the SST signal of the whole North Atlantic sector. For this purpose the AVHRR Pathfinder v5.2 data (quality flag 7 unreconstructed) was retrieved for those days belonging to the P80 and P20 sets. To observe both the developing and decaying phases of the process, negative lags (days after a major IPC-Navidad event) were also taken into account. Figure 11 shows the $\left(\mathrm{C}_{\mathrm{P}-\mathrm{N}}\right)$ patterns for the $-15-0,0-15$ and 15-30 day lag ranges. The SST patterns show an inten- sification and then a decay of the SST signal in the eastern sector. The overall pattern is very consistent with those of the SLA and the surface turbulent fluxes, although the signature also shows marked local differences on the European shelf and more specifically in the Bay of Biscay. For instance, in the north-eastern Atlantic a large-scale heat-flux pattern is observed while the SLA pattern is located on the European shelf.

\section{Discussion}

The first part of this study, devoted to the reconstruction of gappy SST data using the DINEOF technique and the verification of such reconstructions, is of crucial importance for the analysis on the IPC-Navidad carried in the second and third parts, but it is also a valuable scientific result on its own. Although the percentages of missing data were initially very high (up to $93 \%$ ), it was possible to reconstruct between 35 and $45 \%$ of the total days, depending on the reconstruction, with acceptable verification index values, as shown in Table 1. A similar reconstruction based on the 1981-2010 Pathfinder data used here can be found in Esnaola et al. (2012), but for the whole year in that case. The percentage of reconstructed days was higher (above $50 \%$ ) as data for the entire year were considered and the verification indices were also slightly better due to the same reason. A comparison of their results with the results shown in the Table 1 indicates that for the full reconstructed set a BIAS of $-0.18^{\circ} \mathrm{C}$ and a MAD of $0.42^{\circ} \mathrm{C}$ were obtained against the -0.31 and $0.46^{\circ} \mathrm{C}$ analogues derived here. It has to be stressed that in Esnaola et al. (2012) the background error given by the comparison of in situ ICOADS data and the originally nonmissing satellite data was also lower $\left(-0.12\right.$ and $0.35^{\circ} \mathrm{C}$ BIAS and MAD values compared to our -0.19 and $0.47^{\circ} \mathrm{C}$ values). Consequently, the quality of the reconstruction can be considered in the range of the previous reconstructions for this area. Additional confirmation of the quality of the reconstructions was also provided by the spatial error maps given in Fig. 2 and by the time evolutions of the error displayed in Fig. 3.

The joint use of infrared and microwave SST images in the framework of the DINEOF reconstruction technique is a novel approach that was applied in this study for the Bay of Biscay area. Previous multi-variable approaches have been developed in the context of DINEOF (Alvera-Azcárate et al., 2007), but not for the combination used in this study, that had only been applied in the two-dimensional variational data assimilation (2DVAR) context (Chao et al., 2009). This combination allowed us the reconstruction of an additional $4 \%$ of the days without any impact on the verification skill indices (Table 1). In the second and third parts of the present study, where the analysis was focused on the IPC-Navidad, this combined reconstruction lost prominence in favour of the considerably longer 1981-2010 reconstruction. It has to 

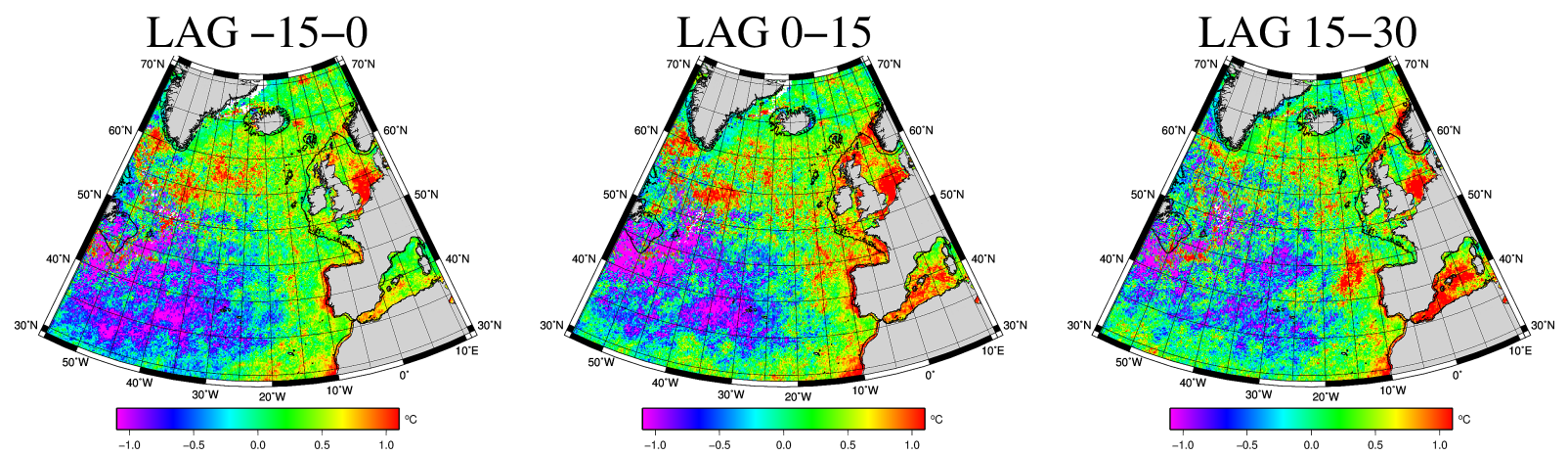

Fig. 11. Composite results based on the IPC-Navidad time series shown in Fig. 7 for the flag 7 un-reconstructed Pathfinder v5.2 SST anomaly data. $-15-0,0-15$ and 15-30 day lag ranges are taken into account.

be pointed out, however, that the IPC-Navidad evolution time series obtained from this reconstruction (Fig. 7, blue points) shows a good agreement with the one derived from the longer time series. Consequently, this combined infrared and microwave SST reconstruction approach has shown to be a valuable methodological improvement that will gain potential as the microwave image series become longer. Additional combined approaches, such as combining SST data with altimetry, or other satellite-derived surface products could prove to be valuable for studies related to the IPC-Navidad and the wintertime SST variability in the Bay of Biscay area.

Once the SST reconstructions were computed and verified, a PCA analysis was applied to isolate the main variability mode. This mode was then subjected to an exhaustive comparison with previous works on the IPC and IPC-Navidad. The shape of the related spatial pattern showed the strongest anomalies near the western Iberian coast, then weakened in the central part of the northern coast to be reinforced again by the east of the Bay and to the north. Unexpectedly, the strongest SST anomaly signal was not located over the slope area, which is possibly related to the presence of part of the IPC-Navidad signal in the climatology and the spatial asymmetry of IPC-Navidad and non-ICP-Navidad conditions, but not to the inclusion of the over-shelf pixels in the PCA. The shape of the EOF could be well related to the climatological mean of the wind-stress curl (Le Cann and Serpette, 2009), to its composite anomaly pattern shown in Fig. 10d, and to the shape and narrowness of the continental shelf together with the baroclinicity of the flow over this area.

The comparison of individual detections of the surface signal of the IPC based on SST images in previous studies (Table 2) showed a clear agreement with our estimations of the interannual variability of the IPC-Navidad shown in Fig. 7. For some studies focused only on the surface signal of the IPC in the western Iberian area (Peliz et al., 2003, 2005), as well as its variability over this area (Peliz et al., 2005; deCastro et al., 2011), the agreement was found to be not as good. This can be explained by the fact that our EOF analysis points to well developed events (those entering the inner
Bay, i.e. Navidad or IPC-Navidad events), which do not have to necessarily match all events at the western coast. Relative to the IPC-Navidad event occurrence and strength described in Garcia-Soto (2004), the main disagreement is found for the 2001/2002 winter, where the number of reconstructed days is small, and thus our series is not giving much information. Another winter that should be considered with care is $1998 / 1999$. In general, major discrepancies between the time series presented in Fig. 7 and previous works seem to take place during months with a limited number of reconstructed days and for weak IPC-Navidad events. Future contributions sharing the approach proposed in this work should pay special attention to those aspects in order to refine the methodology proposed here.

Differences were also found between our IPC-Navidad series and the estimation by Le Hénaff et al. (2011). This is not surprising, however, as discrepancies also occur between their two estimated series, and also because there are large methodological differences with our analysis. Their methodology was focused on a single satellite track where the geostrophic current anomalies where deduced. Conversely, our study is focused on a large area. Additionally, the SST anomaly was also computed across the same track as the difference between SST in the areas expected to be affected by the current (between $200 \mathrm{~m}$ and $1500 \mathrm{~m}$ isobaths) and SST in open-ocean areas, but this was done based on a very small number of satellite SST estimations. The methodology proposed by these authors is promising but suffers from the limited availability of SST data. In fact, this problem can be bypassed using a data reconstruction strategy like the one presented here. The results from such a combination would then be comparable to the estimation of the IPC-Navidad from a PCA analysis. More general combinations of SST and geostrophic current anomaly data could also be explored to target joint detection of the IPC-Navidad signal, e.g. in the form of a combined PCA or a canonical correlation analysis (Wilks, 2006).

The November to February period used in this study has shown to be a good time frame in which to study the 
variability of the IPC-Navidad in the context of a PCA analysis. However, in some of the strongest IPC-Navidad developments shown in Fig. 7 (1997/1998, 2002/2003, 2005/2006, 2006/2007) it fails to capture the onset phase of the process, which seems to have occurred during October or earlier (see e.g. Le Cann and Serpette, 2009, for the 2006/2007 onset). The role of an early IPC development on its subsequent strength is a subject that should be addressed by future studies. However, the results shown here suggest that in some cases the extension of the analysis described here including October could be interesting. Nevertheless, the inclusion of all October months could potentially affect the results of the EOF analysis. This is, therefore, an interesting point for future studies.

The exhaustive checking and comparisons with previous studies have shown a very high level of coherence in most of the cases, confirming our hypothesis that the interannual variability of the surface signal of the IPC can be characterised by the series in Fig. 7 .

The combination of results in Fig. 9 for areas I and IV is very consistent with the water mass analysis of cruise data (Oct-Nov 1999) carried out by Torres and Barton (2006) for the onset and preliminary development stages of the IPC on the western Iberian coast. Related to the decadal changes in the ventilation conditions of the $\mathrm{ENAW}_{\mathrm{P}}$, especially due to strong winter mixing, Pérez et al. (1995) and Pollard et al. (1996) found a shift in water characteristics towards more saline or colder waters relative to the ENAW definition. This is not the case, or at least it is not clear, for the $T / S$ diagrams in Fig. 9, where such decadal variability may have been blurred due to the inclusion of only part of the data (those belonging to the P20 and P80 sets) from 3 different decades. If data over the entire 1981-2010 period is used to deduce the trends in temperature and salinity in areas I, II and III, positive trends are deduced for both variables at several depths (not shown), but the effect of such trends in the analysis shown here is a matter that should be investigated in future studies.

A subsurface salinity maximum located near the slope has already been identified as a tracer of the poleward flow near the Iberian coast (Frouin et al., 1990; Torres and Barton, 2006). For well developed IPC conditions, Torres and Barton (2006) found this maximum to be well defined by both the northern and western Iberian coasts. Results for areas I and II in Figs. 8 and 9 show that the salinity maximum is detected in both cases. Le Cann and Serpette (2009) showed that the sub-surface salinity maximum both weakens and looses seaward extension from the slope as the current moves eastward along the northern Iberian coast. This can explain the fact that it was not detected in area III. The presence of the subsurface salinity maximum and the coherence of the results shown here with those from previous studies further support the validity of the time series given in Fig. 7 .

It is interesting to point out that almost all the values related to the western Iberian coast P20 (area I) lay below the
ENAW and that the related P20 mean vertical temperature and salinity profiles (Fig. 8) showed colder but saltier waters. The $T / S$ diagram for area IV does not show analogously enhanced salinity values. This rules out a southward advection, but it does show slightly higher salinity in the upper metres (Fig. 8). This result could indicate that a local salinification takes place in winter near the western Iberian coast in strong non-IPC years.

In summary, the analysis of the properties of the water masses in winters with extreme values of the IPC-Navidad series has provided additional confirmation of the validity of that time series.

Once it was well established that the interannual variability of the IPC-Navidad can be characterised by the series in Fig. 7, a composite analysis was carried out to try to find relations with variables that could have some influence forcing such variability. This composite analysis, summarised in Figs. 10 and 11, revealed a very coherent scenario between the ocean surface atmospheric variables, ocean surface altimetry and temperature characteristics, and also the $500 \mathrm{hPa}$ level atmospheric circulation anomalies. These act jointly to create the conditions that favour the development of IPC events. In addition, this set of composite patterns is able to confirm the presence of several mechanisms that had been separately proposed to be related to the variability of the IPC. Our analysis suggests that a combined physical mechanism emerges as discussed below.

Figure 10 shows that a circulation anomaly becomes apparent on the $500 \mathrm{hPa}$ level with an associated anomaly on the approximated location of the North Atlantic storm track. This circulation pattern shows a complex relationship with the most common Northern Hemisphere teleconnection patterns, as was shown in Sect. 3.3. Related to the $500 \mathrm{hPa}$ circulation anomaly, pressure, heat-flux and wind-stress anomalies are observed on the surface level. The surface pressure and wind-stress anomalies show anomalous south-westerlies over the Bay of Biscay area. This result is in agreement with many previous studies (e.g. Frouin et al., 1990; Torres et al., 2003; deCastro et al., 2011) that related the IPC occurrences to southerly or south-westerly wind anomalies. In addition to the surface wind anomalies, the surface heat-flux anomalies were also considered here in the context of the IPC. The heat-flux anomaly patterns shown in Fig. 10b are the consequence of the meridional anomalous advection of humidity and heat induced by the already mentioned surface pressure and wind-stress anomalies. Accordingly, the surface heatflux anomalies are negative in the west and positive in the east, indicating an anomalous loss and gain of energy by the ocean (SST decrease and increase, hence) correspondingly (Cayan, 1992a,b,c; Zorita et al., 1992; Esnaola et al., 2012, among others). Meanwhile, the surface heat-flux anomalies also show a very good correspondence with the SLA patterns at a large scale, although some local differences are also observed. Those show a west-east dipole structure that indicates an anomalous anticlockwise geostrophic circulation, 
with a poleward flow on the eastern North Atlantic. As previously indicated, these large-scale patterns also have a gradient of steric sea level associated on the western Iberian coast, indicating JEBAR favourable conditions over that area (Huthnance, 1984, 1995; Torres and Barton, 2006). Finally, this western Iberian area seems to be also related to positive wind-stress curl anomalies that would reinforce the already positive climatological (Le Cann and Serpette, 2009) mean and favour the poleward flow due to the topographic $\beta$ effect.

Some concern may arise related to the fact that the composite analysis is based on a time series that is deduced from the SST anomalies covering a very localised area in the Bay of Biscay, and to whether the analysis would considerably change if it was based on the SST of another area. This concern can be, however, tempered by the fact that the largescale patterns of the different variables shown in Figs. 10 and 11 are very coherent among themselves. Then, the determination of whether the local differences observed among those patterns are consequence of the applied methodology, or to local responses should be determined by future studies.

Using thermal satellite observations, Garcia-Soto et al. (2002) and Garcia-Soto and Pingree (2012) demonstrated that the poleward current can extend from Portugal to Scotland in particular years (e.g. 1990 and 1998 Januaries), showing large poleward SST patches when favourable meteorological conditions occur. They called this the European poleward current, whose Iberian margin branch would be the IPC. Fig. 11 shows the SST anomaly patterns related to the patterns shown in Fig. 10. Despite some local differences observed, those patterns are in very good agreement with the surface atmospheric anomaly patterns and the SLA patterns. Over the eastern North Atlantic slopes north of the Iberian Peninsula, the evolution of SST anomalies suggests some evidence of the European poleward current. However, further research is needed to check the validity of this hypothesis.

The analysis of the patterns shown in Fig. 10 and their analogues with lags going further back in time, indicated strong persistence properties for the atmospheric variables and slightly weaker persistence properties for the SLA patterns. This was also the case for the gradient of steric sea level by the western Iberian coast. In the case of the SST anomalies over the Iberian shelf and slope (Fig. 11), the evolution phase seems to develop mostly in the $0-15$ day range. The time interval of the decay also seems to be in the same range. This would indicate that the atmospheric anomaly patterns need to be persistent enough (up to 60-90 days) to force the oceanic conditions that favour the development of the IPC.

The cause of the altimetry anomalies observed in Fig. 10c could be attributed to the action of the surface turbulent fluxes and the surface wind stress shown in Fig. 10b, or to both. The good resemblance of the geostrophic current patterns shown in Fig. 10d with the current pattern obtained by Pingree and Le Cann (1989) for constant south-westerly winds (like the ones shown in Fig. 10b) also points to that conclusion. The eastern North Atlantic sea level variability at decadal scales was found to be related to the variability of the alongshore wind component and the heat fluxes in Calafat et al. (2012). They concluded that, for such decadal scales, the influence of the alongshore wind component dominates over the influence of heat fluxes. It is not clear, however, if that is the case for the shorter timescale altimetry and geostrophic current anomalies studied here, so future studies should deal with the determination of the relative strengths of the heat-flux and wind-stress anomalies. It is worth mentioning, that such future studies should also determine if the eddy-like structures observed in the current anomaly patterns, especially those north of the Iberian coast, are physically meaningful (i.e. are related to eddies) or just an artifact of the composite analysis.

A relation of a weakened North Atlantic gyre and the development of the IPC was first pointed by Pingree (2002). Later, Garcia-Soto and Pingree (2012) showed the changes in the long-term NAO conditions from high (1993-1995) to low (1995-1997) values, and the ensuing changes in the SLA and SST patterns, associated with a weakening of the North Atlantic gyre. Their SLA and SST anomaly patterns, differences between 1995 and 1998 January means, are very consistent with our slightly weaker patterns in Figs. 10c and 11. It should be noted that despite the good resemblance, some caution is needed. Their analysis was based on a particular period and attributed the differences to the long-term integrated response of the ocean to dominating positive or negative NAO phases in previous years. Conversely, our results are based on a longer analysis period and suggest a shorter response timescale. This does not necessarily mean that the two results exclude each other, as the mechanism of integrated anomalies proposed by Garcia-Soto and Pingree (2012) could be conditioning the selection of the P80 and P20 sets. The determination of the relative role of these longterm modulations on the shorter timescales, that have been shown to be statistically significant in this study, will be an encouraging challenge for future studies.

\section{Conclusions}

Wintertime DINEOF reconstructions of the Pathfinder v5.2 1981-2010 SST data and the combined 2002-2010 Pathfinder v5.2 and AMSR-E SST data were validated using in situ data. Similar verification indices were deduced for both the combined and non-combined DINEOF reconstructions. This means that, when available, microwave SST images could be used as a complementary source of information when reconstructing infrared SST images, allowing a major percentage of SST images to be reconstructed.

The IPC-Navidad was found to be well determined by the first mode ( $49 \%$ of the variance) of a PCA analysis conducted on the reconstructed 1981-2010 Pathfinder v5.2 
SST data and the 2002-2010 combined Pathfinder v5.2 and AMSR-E SST data, restraining the SST to shelf and shelfbreak areas in both cases. The first PC or time series that characterised the variability of the IPC-Navidad during the winters in the 1981-2010 period was exhaustively compared with results from previous studies that are summarised in Table 2 to conclude in a very good agreement in general. The vertical temperature and salinity distributions related to the extremes of that time series also confirmed its validity. In consequence, the time series shown in Fig. 7 was found to characterise reasonably well the wintertime evolution of the IPC-Navidad in the 1981-2010 period.

A physical mechanism that jointly takes into account both the atmosphere and the ocean was presented in relation to the variability of the IPC and its surface signal. Previous studies had related the variability of the IPC to the occurrence of south-westerly winds, to the JEBAR effect, to the topographic $\beta$ effect, to a weakened North Atlantic gyre and also to different North Atlantic atmospheric teleconnection patterns. The joint physical mechanism presented here shows a mutually coherent set of patterns of SST, SLA and ocean surface atmospheric pressure, wind stress and heat flux over the North Atlantic that possibly have their origin in a $500 \mathrm{hPa}$ circulation anomaly. This circulation anomaly pattern does not show a preferred relation with any of the most common North Atlantic teleconnection patterns. Related to these North Atlantic-scale patterns, conditions for a weakened North Atlantic gyre were obtained. In addition, local characteristics of these patterns indicate south-westerly winds, JEBAR and topographic $\beta$ effect favourable conditions over the Bay of Biscay area.

The approach proposed in this contribution has allowed us the study of the wintertime IPC-Navidad phenomenon during the last three decades. The combined use of a missing data reconstruction technique (DINEOF) and a statistical analysis (PCA), has allowed an objective deduction of the variability of this processes during the 1981-2010 winters for the first time at a daily scale. Future directions of the work presented here should deal with three main issues. First, an effort should be made to increase the number of days included in the objective deduction of the IPC-Navidad signal by increasing the number of SST images that is reconstructed. Although limited to the last decade, the joint use of infrared and microwave SST images has been shown to be a valuable alternative in this sense. An alternative reconstruction strategy using SST and SLA data jointly, which would be valuable for the 1992-2010 period, was also proposed in the discussion. A more general approach covering the entire period analysed could also be the use of in situ data from ICOADS and WOD datasets to try to reconstruct the images that cannot be reconstructed by means of the DINEOF technique. This procedure, if successful, could also allow us to go further back in time to the period where satellite SST retrievals are not available but in situ data exist. The second main issue that future works should deal with is the improvement of the de- tection of the IPC-Navidad signal in the reconstructed SST data, especially for most cloudy winters and those with weak IPC-Navidad events. Working lines in this topic should include a more effective removal of the seasonal signal of the IPC-Navidad from the climatology used to deduce the SST anomalies. Other alternatives to the PCA approach used here, like the joint detection of the IPC-Navidad signal in SST and SLA data using a combined PCA or CCA (Canonical Correlation Analysis) techniques proposed in the discussion, could be valuable tools. The third, and last, main issue that future working lines could include is a deepening in the understanding of the atmospheric circulation anomalies that influence the IPC-Navidad variability, and that have been analysed here. These have shown persistent properties that could involve some predictive skills, and hence, potential applications in that sense.

Acknowledgements. ERA-Interim data were obtained from the ECMWF data server (http://data.ecmwf.int/data). Pathfinder v5.2 data were provided by GHRSST and the US National Oceanographic Data Center. AMSR-E data are produced by Remote Sensing Systems and sponsored by the NASA Earth Science MEaSUREs DISCOVER Project and the AMSR-E Science Team. Data are available at www.remss.com. The altimeter products were produced by Ssalto/Duacs and distributed by Aviso, with support from Cnes (http://www.aviso.oceanobs.com/duacs/). ICOADS data for this study have been retrieved from the Research Data Archive (RDA) which is maintained by the Computational and Information Systems Laboratory (CISL) at the National Center for Atmospheric Research (NCAR). Word Ocean Database data were obtained from http://www.nodc.noaa.gov/OC5/WOD/pr_wod.html. DINEOF source code is freely available at http://modb.oce.ulg. ac.be/mediawiki/index.php/DINEOF. G. Esnaola is supported by a research grant (Interacción Atmósfera-Océano en el Golfo de Bizkaia) from Fundación Centros Tecnológicos Iñaki Goenaga. Jon Sáenz would like to thank the financial support from project CGL2008-03321 (Spanish National R+D+I Programme). He also thanks funding provided by the University of the Basque Country (UFI 11/55, PPH12/01 and GIU 11/01). The Basque Government (Department of Agriculture, Fisheries and Food) has funded the project VARIACIONES. The authors want to express their gratitude to A. Caballero from AZTI-Tecnalia for her help with the Altimetry data and to B. Le Cann from UBO-CNRS-IRD-IFREMER for his useful comments on an early draft of this document. This is contribution number 649 of the Marine Research Division of AZTI-Tecnalia.

Edited by: M. Hoppema 


\section{References}

Alvera-Azcárate, A., Barth, A., Rixen, M., and Beckers, J. M.: Reconstruction of incomplete oceanographic data sets using empirical orthogonal functions: application to the Adriatic Sea surface temperature, Ocean Model., 9, 325-346, 2005.

Alvera-Azcárate, A., Barth, A., Beckers, J. M., and Weisberg, R. H.: Multivariate reconstruction of missing data in sea surface temperature, chlorophyll, and wind satellite fields, J. Geophys. Res.Oceans, 112, 2007.

Alvera-Azcárate, A., Barth, A., Sirjacobs, D., and Beckers, J.-M.: Enhancing temporal correlations in EOF expansions for the reconstruction of missing data using DINEOF, Ocean Sci., 5, 475485, doi:10.5194/os-5-475-2009, 2009.

AVISO: SSALTO/DUACS User Handbook: (M)SLA and (M)ADT Near-Real Time and Delayed Time Products, SALP-MU-PEA-21065-CLS, Edition 3.1, http://www.aviso.oceanobs.com/ fileadmin/documents/data/tools/\%hdbk_duacs.pdf, 2012.

Beckers, J. M. and Rixen, M.: EOF calculations and data filling from incomplete oceanographic datasets, J. Atmos. Ocean. Tech., 20, 1839-1856, 2003.

Beckers, J.-M., Barth, A., and Alvera-Azcárate, A.: DINEOF reconstruction of clouded images including error maps - application to the Sea-Surface Temperature around Corsican Island, Ocean Sci., 2, 183-199, doi:10.5194/os-2-183-2006, 2006.

Calafat, F. M., Chambers, D. P., and Tsimplis, M. N.: Mechanisms of decadal sea level variability in the eastern North Atlantic and the Mediterranean Sea, J. Geophys. Res., 117, C09022, doi:10.1029/2012JC008285, 2012.

Casey, K. S., Brandon, T. B., Cornillon, P., and Evans, R.: The Past, Present and Future of the AVHRR Pathfinder SST Program, in: Oceanography from Space: Revisited, edited by: Barale, V., Gower, J. F. R., and Alberotanza, L., Springer, doi:10.1007/97890-481-8681-5_16, 2010.

Cayan, D. R.: Variability of Latent and Sensible Heat Fluxes Estimated using Bulk Formulas, Atmos. Ocean, 30, 1-42, doi:10.1080/07055900.1992.9649429, 1992a.

Cayan, D. R.: Latent and Sensible Heat Flux Anomalies over the Northern Oceans: The Connection to Monthly Atmospheric Circulation, J. Climate, 5, 354-369, doi:10.1175/15200442(1992)005<0354:LASHFA > 2.0.CO;2, 1992 b.

Cayan, D. R.: Latent and Sensible Heat Flux Anomalies over the Northern Oceans: Driving the Sea Surface Temperature, J. Phys. Oceanogr., 22, 859-881, doi:10.1175/15200485(1992)022<0859:LASHFA > 2.0.CO;2, 1992c.

Chao, Y., Li, Z., Farrara, J. D., and Hung, P.: Blending Sea Surface Temperatures from Multiple Satellites and In Situ Observations for Coastal Oceans, J. Atmos. Ocean. Tech., 26, 14151426, doi:10.1175/2009JTECHO592.1, 2009.

Coelho, H. S., Neves, R. R., Leitao, P. C., Martins, H., and Santos, A. P.: The slope current along the western European margin: A numerical investigation, Bol. Inst. Espan. Oceanogr., 15, 61-72, 1999.

deCastro, M., Gómez-Gesteira, M., Álvarez, I., and Crespo, A. J. C.: Atmospheric modes influence on Iberian Poleward Current variability, Cont. Shelf Res., 31, 425-432, 2011.

Esnaola, G., Sáenz, J., Zorita, E., Lazure, P., Ganzedo, U., Fontán, A., Ibarra-Berastegi, G., and Ezcurra, A.: Coupled air-sea interaction patterns and surface heat-flux feedback in the Bay of Biscay, J. Geophys. Res.-Oceans, 117, C06030,
doi:10.1029/2011JC007692, 2012.

Frouin, R., Fiuza, A., Ambar, I., and Boyd, T.: Observations of a poleward surface current off the coasts of Portugal and Spain during winter, J. Geophys. Res.-Oceans, 95, 679-691, 1990.

Ganzedo, U., Alvera-Azcárate, A., Esnaola, G., Ezcurra, A., and Sáenz, J.: Reconstruction of sea surface temperature by means of DINEOF: a case study during the fishing season in the Bay of Biscay, Int. J. Remote Sens., 32, 933-950, 2011.

Garcia-Soto, C.: "Prestige" oil spill and Navidad flow, J. Mar. Biol. Assoc. UK, 84, 297-300, 2004.

Garcia-Soto, C. and Pingree, R. D.: Atlantic Multidecadal Oscillation (AMO) and sea surface temperature in the Bay of Biscay and adjacent regions, J. Mar. Biol. Assoc. UK, 92, 213-234, 2012.

Garcia-Soto, C., Pingree, R. D., and Valdés, L.: Navidad development in the southern Bay of Biscay: Climate change and swoddy structure from remote sensing and in situ measurements, J. Geophys. Res.-Oceans, 107, 3118, doi:10.1029/2001JC001012, 2002.

Gil, J.: Changes in the pattern of water masses resulting from a poleward slope current in the Cantabrian Sea (Bay of Biscay), Estuar. Coast. Shelf S., 57, 1139-1149, 2003.

Haynes, R. and Barton, E.: A poleward flow along the Atlantic coast of the Iberian peninsula, J. Geophys. Res.-Oceans, 95, 1142511441, 1990.

Herbert, G., Ayoub, N., Marsaleix, P., and Lyard, F.: Signature of the coastal circulation variability in altimetric data in the southern Bay of Biscay during winter and fall 2004, J. Mar. Syst., 88, 139158, 2011.

Huthnance, J.: Slope Currents and JEBAR, J. Phys. Oceanogr., 14, 795-810, 1984.

Huthnance, J. M.: Circulation, exchange and water masses at the ocean margin: the role of physical processes at the shelf edge, Progr. Oceanogr., 35, 353-431, 1995.

Johnson, D. R., Boyer, T. P., Garcia, H. E., Locarnini, R. A., Baranova, O. K., and Zweng, M. M.: World Ocean Database 2009 Documentation, NODC Internal Report 20, 2009.

Kilpatrick, K. A., Podestá, G. P., and Evans, R.: Overview of the NOAA/NASA advanced very high resolution radiometer Pathfinder algorithm for sea surface temperature and associated matchup database, J. Geophys. Res., 106, 9179-9197, 2001.

Koutsikopoulos, C. and LeCann, B.: Physical processes and hydrological structures related to the Bay of Biscay anchovy, Sci. Mar., 60, 9-19, 1996.

Lau, N.-C.: Variability of the Observed Midlatitude Storm Tracks in Relation to Low-Frequency Changes in the Circulation Pattern, J. Atmos. Sci., 45, 2718-2743, doi:10.1175/15200469(1988)045<2718:VOTOMS>2.0.CO;2, 1988.

Le Cann, B. and Serpette, A.: Intense warm and saline upper ocean inflow in the southern Bay of Biscay in autumn-winter 20062007, Cont. Shelf Res., 29, 1014-1025, 2009.

Le Hénaff, M., Roblou, L., and Bouffard, J.: Characterizing the Navidad current interannual variability using coastal altimetry, Ocean Dynam., 61, 425-437, 2011.

Llope, M., Anadón, R., Viesca, L., Quevedo, M., González-Quirós, R., and Stenseth, N. C.: Hydrography of the southern Bay of Biscay shelf-break region: Integrating the multiscale physical variability over the period 1993-2003, J. Geophys. Res.-Oceans, 111, C09021, doi:10.1029/2005JC002963, 2006. 
McCartney, M. S. and Talley, L. D.: The Sub-polar Mode Water of the North-atlantic Ocean, J. Phys. Oceanogr., 12, 1169-1188, doi:10.1175/1520-0485(1982)012<1169:TSMWOT>2.0.CO;2, 1982.

Michel, S., Treguier, A. M., and Vandermeirsch, F.: Temperature variability in the Bay of Biscay during the past 40 years, from an in situ analysis and a 3D global simulation, Cont. Shelf Res., 29, 1070-1087, 2009.

Peliz, A., Dubert, J., Haidvogel, D. B., and Le Cann, B.: Generation and unstable evolution of a density-driven Eastern Poleward Current: The Iberian Poleward Current, J. Geophys. Res.-Oceans, 108, 3268, doi:10.1029/2002JC001443, 2003.

Peliz, A., Dubert, J., Santos, A. M. P., Oliveira, P. B., and Le Cann, B.: Winter upper ocean circulation in the Western Iberian Basin Fronts, Eddies and Poleward Flows: an overview, Deep-Sea Res. Pt. I, 52, 621-646, 2005.

Pérez, F. F., Ríos, A. F., King, B. A., and Pollard, R. T.: Decadal changes of the 0-8 relationship of the eastern North Atlantic central water, Deep-Sea Res. Pt. I, 42, 1849-1864, 1995.

Pérez, F. F., Pollard, R. T., Read, J. F., Valencia, V., Cabanas, J. M., and Rios, A. F.: Climatological coupling of the thermohaline decadal changes in Central Water of the Eastern North Atlantic, Sci. Mar., 64, 347-353, 2000.

Pingree, R.: Flow of surface waters to the west of the British Isles and in the Bay of Biscay, Deep-Sea Res. Pt. II, 40, 369-388, 1993.

Pingree, R.: Winter warming in the southern Bay of Biscay and Lagrangian eddy kinematics from a deep-drogued ARGOS buoy, J. Mar. Biol. Assoc. UK, 74, 107-128, doi:10.1017/S0025315400035700, 1994.

Pingree, R.: Ocean structure and climate (Eastern North Atlantic): in situ measurement and remote sensing (altimeter), J. Mar. Biol. Assoc. UK, 82, 681-707, 2002.

Pingree, R. D. and Le Cann, B.: Celtic and Armorican slope and shelf residual currents, Progr. Oceanogr., 23, 303-338, 1989.

Pingree, R. D. and Le Cann, B.: Structure, strength and seasonality of the slope currents in the Bay of Biscay region, J. Mar. Biol. Assoc. UK, 70, 857-885, 1990.

Pingree, R. and Le Cann, B.: Anticyclonic eddy X91 in the southern Bay of Biscay, May 1991 to February 1992, J. Geophys. Res.Oceans, 97, 14353-14367, 1992a.

Pingree, R. and Le Cann, B.: Three anticyclonic slope water oceanic EDDIES (SWODDIES) in the Southern Bay of Biscay in 1990, Deep-Sea Res., 39, 1147-1175, 1992 b.

Pingree, R., Sinha, B., and Griffiths, C.: Seasonality of the European slope current (Goban Spur) and ocean margin exchange, Cont. Shelf Res., 19, 929-975, doi:10.1016/S0278-4343(98)00116-2, 1999.

Pollard, R. T., Griffiths, M. J., Cunningham, S. A., Read, J. F., Pérez, F. F., and Ríos, A. F.: Vivaldi 1991-A study of the formation, circulation and ventilation of Eastern North Atlantic Central Water, Progr. Oceanogr., 37, 167-192, 1996.
Relvas, P., Barton, E. D., Dubert, J., Oliveira, P. B., Peliz, A., da Silva, J. C. B., and Santos, A. M. P.: Physical oceanography of the western Iberia ecosystem: Latest views and challenges, Progr. Oceanogr., 74, 149-173, 2007.

Reverdin, G., Cayan, D., Dooley, H. D., Ellett, D. J., Levitus, S., Dupenhoat, Y., and Dessier, A.: Surface Salinity of the Northatlantic - Can We Reconstruct Its Fluctuations Over the Last 100 Years, Progr. Oceanogr., 33, 303-346, doi:10.1016/00796611(94)90021-3, 1994.

Ríos, A., Pérez, F., and Fraga, F.: Water masses in the upper and middle North Atlantic Ocean east of the Azores, Deep-Sea Res., 39, 645-658, 1992.

Rogers, J. C.: North Atlantic storm track variability and its association to the north Atlantic oscillation and climate variability of northern Europe, J. Climate, 10, 1635-1647, 1997.

Rogers, J. C. and Van Loon, H.: Seesaw In Winter Temperatures Between Greenland and Northern Europe .2. Some Oceanic and Atmospheric Effects In Middle and Highlatitudes, Mon. Weather Rev., 107, 509-519, doi:10.1175/15200493(1979)107<0509:TSIWTB > 2.0.CO;2, 1979.

Sánchez, R. F., Relvas, P., and Delgado, M.: Coupled ocean wind and sea surface temperature patterns off the western Iberian Peninsula, J. Mar. Syst., 68, 103-127, 2007.

Simmons, A., Uppala, S., Dee, S., and Kobayashi, S.: ERAInterim: New ECMWF re-a-na-ly-sis products from 1989 onwards, ECMWF Newsletter, Winter 2006/7, 25-35, 2007.

Torres, R. and Barton, E. D.: Onset and development of the Iberian poleward flow along the Galician coast, Cont. Shelf Res., 26, 1134-1153, 2006.

Torres, R., Barton, E. D., Miller, P., and Fanjul, E.: Spatial patterns of wind and sea surface temperature in the Galician upwelling region, J. Geophys. Res.-Oceans, 108, 2003.

von Storch, H. and Zwiers, F. W.: Statistical analysis in Climate Research, Cambridge University Press, doi:10.2277/0511037538, 1999.

Wilks, D. S.: Statistical Methods in the Atmospheric Sciences, in: International Geophysics Series, vol. 59, Academic Press, doi:10.1002/met.16, 2006.

Woodruff, S. D., Worley, S. J., Lubker, S. J., Ji, Z., Freeman, J. E., Berry, D. I., Brohan, P., Kent, E. C., Reynolds, R. W., Smith, S. R., and Wilkinson, C.: ICOADS Release 2.5: extensions and enhancements to the surface marine meteorological archive, Int. J. Climatol., 31, 951-967, 2011.

Worley, S. J., Woodruff, S. D., Reynolds, R. W., Lubker, S. J., and Lott, N.: ICOADS release 2.1 data and products, Int. J. Climatol., 25, 823-842, 2005.

Zorita, E., Kharin, V., and von Storch, H.: The Atmospheric Circulation and Sea Surface Temperature in the North Atlantic Area in Winter: Their Interaction and Relevance for Iberian Precipitation, J. Climate, 5, 1097-1108, doi:10.1175/15200442(1992)005<1097:TACASS > 2.0.CO;2, 1992. 